\title{
ESTIMATING MARKET POWER IN HOMOGENOUS PRODUCT MARKETS USING A COMPOSED ERROR MODEL: APPLICATION TO THE CALIFORNIA ELECTRICITY MARKET ${ }^{*}$
}

\author{
Luis Orea \\ University of Oviedo, Spain \\ lorea@uniovi.es \\ Jevgenijs Steinbuks \\ Purdue University, USA \\ jsteinbu@purdue.edu
}

December 1, 2011

\begin{abstract}
This study contributes to the literature on estimating market power in homogenous product markets. We estimate a composed error model, where the stochastic part of the firm's pricing equation is formed by two random variables: the traditional error term, capturing random shocks, and a random conduct term, which measures the degree of market power. Treating firms' conduct as a random parameter helps solving the over-parameterization problem in the continuous time. We apply our model to the California wholesale electricity market, and obtain time-varying and firmspecific conduct parameters. We find that firms' pricing strategies are Cournot except for the period of price run-up in summer 2000, and firms' conduct is procyclical. Firms' potential for realization of the market power unilaterally is generally associated with lower values of the conduct parameter, indicating that the unilateral exercise of market power and collusive behaviour are substitutes.
\end{abstract}

Keywords: market power, random conduct parameter, composed error model, asymmetric distributions, California electricity market.

JEL codes: C34, C51, L13, L94

\footnotetext{
* Acknowledgements: The authors would like to express their sincere gratitude to Ben Hobbs for his invaluable help and support. We are extremely grateful to Steve Puller and Carolyn Berry for helping us with getting CEMS and California PX bidding data, and to Chiara Lo Prete for assisting us with computation of residual demand elasticities based on PX bidding data. We also thank David Newbery, Jacob LaRiviere and the participants of the $3^{\text {rd }}$ International Workshop on Empirical Methods in Energy Economics and the 9th Annual International Industrial Organization Conference for their helpful comments and suggestions. All remaining errors are ours. Jevgenijs Steinbuks appreciates the financial support from the UK Engineering and Physical Sciences Research Council, grant "Supergen FlexNet".
} 


\section{Introduction}

Starting from seminal research works of Iwata (1974), Gollop and Roberts (1979), and Appelbaum (1982), measuring the degree of competition in oligopolistic markets has become one of key activities in empirical industrial organization. A large and growing economic literature in New Empirical Industrial Organization (NEIO) relies on structural models to infer what types of firm behaviour ("conduct") are associated with prices that exceed marginal costs. ${ }^{1}$ A typical structural model based on the conduct parameter approach for homogenous product markets starts with specifying a demand function and writing down the first-order condition of firm's profitmaximization problem:

$$
P\left(Q_{t}\right)-m c\left(q_{i t}\right)+P^{\prime}\left(Q_{t}\right) q_{i t} \cdot \theta_{i t}=0,
$$

where $P\left(Q_{t}\right)$ is inverse demand, $Q_{t}=\Sigma_{i}^{N} q_{i t}$ is total industry's output, $q_{i t}$ is the firm's output in period t, $m c\left(q_{i t}\right)$ is the firm's marginal cost, and $\theta_{i t}$ is a "conduct" parameter that parameterizes the firm's profit maximization condition. Under perfect competition, $\theta_{i t}=0$ and price equals marginal cost. When $\theta_{i t}=\mathrm{N}$ we face a perfect cartel, and when $0<\theta_{i t}<\mathrm{N}$ various oligopoly regimes apply. In these models the (firm or industry) degree of market power is measured by a conduct parameter $\theta$ that is jointly estimated with other cost and demand parameters. ${ }^{2}$

The conduct parameter $\theta_{i t}$ may vary across time as market conditions change, and firms change their own pricing strategies. ${ }^{3}$ Moreover, the conduct parameter may also vary across firms as "there is nothing in the logic of oligopoly theory to force all firms to have the same conduct" (Bresnahan, 1989, p. 1030). ${ }^{4}$ Obviously, allowing the conduct parameter to vary both by firms and time-series results in an overparameterized model. To avoid this problem, empirical studies in structural econometric literature always impose some restrictions on the way the value of conduct parameter varies

\footnotetext{
${ }^{1}$ For an excellent survey of other approaches to estimating market power in industrial organization literature, see Perloff et al (2007).

${ }^{2}$ Some studies interpret estimated conduct parameter as a 'conjectural variation', i.e. how rivals' output changes in response to an increase in firm $i$ 's output. Bresnahan (1989) and Reiss and Wolak (2007) argue that with an exception of limited number of special cases (e.g. perfect competition, Cournot-Nash, and monopoly) there is there is no satisfactory economic interpretation of this parameter as a measure of firm behaviour. We therefore interpret this parameter as a simple descriptive measure of firm's degree of market power.

${ }^{3}$ As the problem of repeated oligopoly interaction has received greater attention, the estimation of timevarying conduct parameters that are truly dynamic has become an issue. Indeed, the Stigler's (1964) theory of collusive oligopoly implies that, in an uncertain environment, both collusive and price-war periods will be seen in the data. Green and Porter (1984) predict a procyclical behaviour pattern for markups because of price reversion during a period of low demand. Hence the conduct parameter changes from collusive value to competitive value when there is an unanticipated negative demand shock. On the contrary, Rotemberg and Saloner (1986) predict that prices and mark-ups are countercyclical, and hence the conduct parameter will decrease when demand is high. Moreover, Abreu et al. (1986) find that in complex cartel designs the length of price wars (i.e. changes in conduct parameter) is random because there are "triggers" for both beginning a price war and for ending one. It is therefore difficult to impose plausible structural conditions and estimate firms' conduct over time.

${ }^{4}$ In many treatments of oligopoly as a repeated game, firms expect deviations from the collusive outcome. Firms expect that if they deviate from the collusive arrangement, other will too. This expectation deters them from departing from their share of the collusive output. Because these deviations are unobserved in an uncertain environment, each firm might have its own expectation about what would happen if it deviates from collusive output.
} 
across firms and time. The overparameterization is typically solved by estimating the average of the conduct parameters of the firms in the industry (Appelbaum 1982), reducing the time variation into a period of successful cartel cooperation and a period of price wars or similar breakdowns in cooperation (Porter 1983a), allowing for different conduct parameters between two or more groups of firms (Gollop and Roberts 1979), or assuming firm-specific, but time-invariant, conduct parameters in a panel data framework (Puller 2007).

This study proposes a new econometric approach that deals with overparameterization problem and helps obtaining the values of firm's conduct that vary across both time and market participants. Instead of estimating the firm's conduct as a common parameter together with other parameters defining cost and demand, we propose treating firms' behaviour $\theta_{i t}$ as a random variable. Our approach is based on composed error model, where the stochastic part is formed by two random variables traditional error term, capturing random shocks, and a random conduct term, which measures market power. The model is estimated in three stages. ${ }^{5}$ In the first stage, all parameters describing the structure of the pricing equation (1) are estimated using appropriate econometric techniques. In the second stage, distributional assumptions on random conduct term are invoked to obtain consistent estimates of the parameters describing the structure of the two error components. In the third stage, market power scores are obtained for each firm by decomposing the estimated residual into a noise component and a market-power component.

The main contribution of the proposed approach is about the way the asymmetry of the composed error term is employed to get firm-specific market power estimates. While the first stage of our model is standard, the following stages take advantage of the fact that the distribution of conduct term is truncated and likely positively or negatively skewed. Though the idea of identification of structural econometric models through asymmetries in variance of error term is not new in applied econometric literature ${ }^{6}$, to our knowledge skewness of conduct parameter in oligopolistic industry settings is not examined explicitly in most (if any) of the previous studies.

The proposed approach can be viewed as belonging to the same family as Porter (1983b), Brander and Zhang (1993), and Gallet and Schroeter (1995) who estimate a regime-switching model where market power enters in the model as a supply shock. As in our model, the identification of market power in these studies relies on making assumptions about the structure of unobservable error term. However, while previous papers estimated the pricing relationship (1) assuming $\theta_{i t}=\theta_{t}$ to be a discrete random variable that follows a bimodal distribution ("price wars" vs. "collusion"), here $\theta_{i t}$ varies both across firms and over time and is treated as a continuous random term. Therefore, while the switching regression models can only be estimated when there are discrete "collusive" and "punishment" phases that are either observable or could be inferred

\footnotetext{
${ }^{5}$ As in Porter (1983b), Brander and Zhang (1993), and Gallet and Schroeter (1995), Maximum Likelihood techniques can be used to estimate all parameters of the model in a unique stage. However this does not allow us to address the endogeneity issues that appear when estimating the pricing equation (1). ${ }^{6}$ See Rigobon (2003), and references therein.
} 
from the data, our model can be estimated in absence of regime switches. ${ }^{7}$ The continuous nature of our conduct random term thus allows us to capture gradual changes in firm behaviour. ${ }^{8}$

Another feature that distinguishes our paper from previous studies is the attempt to estimate a double-bounded distribution that imposes both lower and upper theoretical bounds (i.e. $0 \leq \theta_{i t} \leq N$ ) to a continuous random conduct term. To achieve this objective we have explored the stochastic frontier literature, ${ }^{9}$ and adapted the doubly truncated normal distribution recently introduced by Almanidis et al. (2011) to our framework. To our knowledge, this is the first time the stochastic frontier models are used to measure market power. Because our model relies on distributional assumptions on the stochastic part, firm-specific market power estimates can be obtained just using cross-sectional data sets, unlike in previous papers that used a fixed effect treatment to estimate firm average conduct in a panel data framework. Therefore, our approach is especially useful when: $i$ ) no panel data sets are available $\left.;{ }^{10} i i\right)$ the time dimension of the data set is short; 11 iii) the available instruments are valid when estimating a common pricing equation to all observations, but not when we try to estimate separable pricing equations for each firm; or $i v$ ) the assumption of time-invariant conduct is not reasonable.

While economic theory imposes both lower and upper theoretical bounds to the random conduct term, the skewness of its distribution is an empirical issue. We argue, however, that the skewness assumption of the distribution of conduct term is reasonable because oligopolistic equilibrium outcomes often yield skewed conduct random terms where large (collusive) conduct values are either less or more probable than small (competitive) conduct values. For instance, to the dominant firm theory assumes that one (few) firm(s) has enough market power to fix prices over marginal cost. This market power is, however, attenuated by a fringe of (small) firms that do not behave strategically. ${ }^{12}$ The most important characteristic of this equilibrium is that the modal value of the conduct random term (i.e. the most frequent value) is close to zero, and higher values of $\theta_{i t}$ are increasingly less likely (frequent). In other markets all firms

\footnotetext{
${ }^{7}$ The regime switches only occur when a firm's quantity is never observed by other firm and, hence, deviations cannot be directly observed. This is not the case in the electricity generating industry analyzed in the empirical section as market participants had access to accurate data on rivals' real-time generation.

${ }^{8}$ Kole and Lehn (1999) argue that for many firms the decision-making apparatus is slow to changes in the market environment within which it operates, due to the costs to reorient decision-makers to a new "game plan". In particular, the existing culture or the limited experience of the firm in newly restructured markets may be such that strategies to enhance market power may not be immediately undertaken. In addition, we would also expect gradual changes in firms conduct in a dynamic framework if firms are engaging in efficient tacit collusion and are pricing below the static monopoly level, and when there is a high persistence in regimes (Ellison, 1994).

${ }^{9}$ For a comprehensive survey of this literature, see Kumbhakar and Lovell (2000), and Fried et al. (2008).

${ }^{10}$ In particular, our approach is useful in cross-section applications when there is not prior information about the identities of suspected cartel members and hence a benchmark of non-colluding firms is not available.

${ }^{11}$ The fixed-effect treatment is only consistent when long panel data sets are available (i.e. as $\mathrm{T} \rightarrow \infty$ ). In addition, the incidental parameter problem appears, i.e. the number of parameters grows with sample size (i.e. as $\mathrm{N} \rightarrow \infty$ ).

${ }^{12}$ This partial collusion equilibrium is reasonable in markets with many firms where coordination among all firms is extremely difficult to maintain as the number of firms in the collusive scheme is too high or other market characteristics make coordination too expensive, e.g. markets with differentiated products.
} 
might be involved in perfect cartel scheme. In such a cartel-equilibrium, firms usually agree to sell "target" quantities, and the resulting market price is the monopoly price, which is associated with the maximum conduct value, e.g. $\theta_{i t}=\mathrm{N}$. Less values of $\theta_{i t}$ are possible due, for instance, to cheating behaviour. ${ }^{13}$ This means that the modal value of the conduct random term in this equilibrium is one, with less values of $\theta_{i t}$ increasingly less likely. That is, firm-conduct is negative skewed. In general, similar equilibria that yield asymmetric distributions for the firm-conduct parameter with modal values close to zero or to the number of colluding firms may also arise.

We illustrate the model with an application to the California electricity generating market between April 1998 and December 2000. This industry is an ideal setting to apply our model because there were high concerns regarding market power levels in California restructured electricity markets during that period, and detailed price, cost, and output data are available as a result of the long history of regulation and the transparency of the production technology. This data set allows us to compute directly hourly marginal cost and residual demand elasticities for each firm. We can therefore avoid complications from estimating demand and cost parameters and focus our research on market power, avoiding biases due inaccurate estimates of marginal cost and residual demand. ${ }^{14}$ Hence, this data set provides a proper framework to discuss methodological issues and to apply the empirical approach proposed in the present paper. In addition, these data have been used in previous papers to evaluate market power in California electricity market. In particular, Borenstein et al. (2002) and Joskow and Kahn (2001) calculate hourly marginal cost for the California market and compare these estimates to wholesale prices. They find that, in certain time periods, prices substantially exceeded marginal cost. Wolak (2003) calculates the residual demand based on bidding data in California Independent System Operator's (CAISO) real-time energy market. He concludes that the increase in market power in summer 2000 can be attributed to firms' exercise of unilateral market power. Puller (2007) analyses the pricing behaviour of California electricity generating firms and finds that price-cost margins varied substantially over time.

Our first-stage results are generally similar to previous findings of Puller (2007). The estimated market power values are closer to Cournot $\left(\theta_{i t}=1\right)$ than to static collusion $\left(\theta_{i t}=\mathrm{N}\right)$. However, we also find a large increase in estimated conduct parameter of all firms during the period of price run-up in June - November 2000, using more accurate residual demand elasticities based on California Power Exchange bidding data. The analysis of firm-specific conduct parameters suggests that realization of market power varies over both time and firms, and rejects the assumption of a common conduct parameter for all firms. Firms' conduct tends to be procyclical, with the degree of collusive behaviour increasing (declining) during the periods of high (low) electricity demand. Estimated firm-specific conduct parameters generally tend to move in the same

\footnotetext{
${ }^{13}$ It is well known that secret price cuts (or secrete sales) by cartel members are almost always a problem in cartels. For instance, Ellison (1994) finds that secret price cuts occurred during $25 \%$ of the cartel period and that the price discounts averaged about 20\%. See also Borenstein and Rose (1994).

${ }^{14}$ See Kim and Knittel (2006) using data from the California electricity market. See also Genesove and Mullin (1998) and Clay and Troesken (2003) for applications to the sugar and whiskey industries respectively.
} 
direction across time, suggesting that firms pursue similar market strategies as market conditions change.

Finally, we use the estimates of firm-specific conduct parameters to clarify the extent to which firms' potential for exercising market power unilaterally affects their market conduct. Similar to Wolak (2003) we compute the residual demand elasticities facing each firm individually on the California PX market, and use their reciprocals (Lerner indices) as a measure of the firms' potential to exercise unilateral market power. We find that firms' potential for realization of the market power unilaterally is generally associated with lower values of the conduct parameter, indicating that the unilateral exercise of market power and collusive behaviour are substitutes.

The rest of the paper is structured as follows. In Section 2 we describe the empirical specification of the model. In Section 3 we discuss the three-stage procedure to estimate the model. The empirical illustration of the model using California electricity data is described in Section 4. Section 5 concludes.

\section{Empirical Specification}

The traditional structural econometric model of market power is formed by a demand function and a pricing equation. Because we are interested in the estimation of industry or firm-specific market power scores, we only discuss here the estimation of the pricing equation (1), conditional on observed realization of residual demand. ${ }^{15}$ If the demand function parameters are not known, they should be estimated jointly with cost and market power parameters.

In this section we develop a simple model where firms sell homogenous products (e.g. kilowatt-hours of electricity) and choose individual quantities each period so as to maximize their profits. Our model is static as we assume that firms maximize their profits each period without explicit consideration of the competitive environment in other periods. ${ }^{16}$ Firm $i$ 's profit function in period $t$ can be written as:

$$
\pi_{i t}=P\left(Q_{t}\right) \cdot q_{i t}-C\left(q_{i t}, \alpha\right),
$$

where $\hat{\beta}$ is a vector of previously estimated demand parameters, and $\alpha$ is a vector of cost parameters to be estimated. We assume that firms choose different quantities each period and their marginal cost varies across firms and over time.

In a static setting, the firm's profit maximization problem is

\footnotetext{
${ }^{15}$ This is the strategy followed, for instance, by Brander and Zhang (1993), Nevo (2001) and Jaumandreu and Lorences (2002).

${ }^{16}$ Corts (1999) argues that traditional approaches to estimating the conduct parameter from static pricing equations yield inconsistent estimates of the conduct parameter if firms are engaged in an effective tacit collusion. The robustness of the conduct parameter approach depends, in addition, on the discount factor and the persistency of the demand. Puller (2009) derives and estimates a more general model that addresses the Corts critique. The results from estimating the more general model for the California market yielded estimates very similar to the static model. This similarity comes from the fact that "California market [can be] viewed as an infinitely repeated game with a discount factor between days very close to 1 " Puller (2007, p.84). Our empirical application to California electricity market as a static model is therefore sufficient for estimating market power consistently.
} 


$$
\max _{q_{i t}} P\left(Q_{t}, \hat{\beta}\right) \cdot q_{i t}-C\left(q_{i t}, \alpha\right) .
$$

The first order conditions (FOC's) of the static model are captured by equation (1), that is:

$$
P_{t}=m c\left(q_{i t}, \alpha\right)+g_{i t} \cdot \theta_{i t},
$$

where $m c\left(q_{i t}, \alpha\right)$ stands for firm's marginal cost, $g_{i t}=P_{t} q_{i t} / Q_{t} \eta_{i t}^{D}$, and $\eta_{i t}^{D}=P^{\prime}\left(Q_{t}\right) P_{t} / Q_{t}$ is the (observed) elasticity of product demand. The stochastic specification of the above FOC's can be obtained by adding the error term, capturing measurement and optimization errors:

$$
P_{t}=m c\left(q_{i t}, \alpha\right)+g_{i t} \cdot \theta_{i t}+v_{i t} .
$$

Instead of viewing firm's behaviour as a structural parameter to be estimated we here treat firms' behaviour as a random variable. While retaining standard assumption that the error term $v_{i t}$ is i.i.d. and symmetric with zero mean, we also assume that $\theta_{i t}$ follows a truncated distribution that incorporates the theoretical restriction that $0 \leq \theta_{i t} \leq \mathrm{N}$. The distinctive feature of our model is that the stochastic part is formed by two random variables - the traditional symmetric error term, $v_{i t}$, and an asymmetric random conduct term, $g_{i t} \cdot \theta_{i t}$, that reflects the market power. The restriction that the composed error term is asymmetric allows us obtaining separate estimates of $\theta_{i t}$ and $v_{i t}$ from an estimate of the composed error term.

Our static model can be easily adapted to a dynamic framework following Puller (2009). He notices that the dynamic part of the FOC's is common to all firms and, hence, Corts' critique can be avoided by estimating the pricing equation (4) with a set of time-dummy variables. Because firm's dynamic behaviour is affected by current demand, expected future demand, and expected future costs (Borenstein and Shephard, 1996), consistent estimates can be also obtained by replacing the set of dummy variables by a function of expected demand and cost shocks measured relative to current demand and costs. ${ }^{17}$

Challenges are greater if we want to estimate a general specification that includes conduct determinants, i.e. $\theta_{i t}=\theta_{i t}\left(z_{i t}\right)$, where $z_{i t}$ might include expected future demand and expected future costs as suggested by the economic theory, in addition to other determinants of firms' behaviour. It is worthy to note that in this general specification the conduct determinants affect both the shape and magnitude of the asymmetric random conduct term, and their coefficients must be estimated using maximum likelihood (ML) techniques. In an important special case, if $\theta_{i t}$ satisfies the so-called scaling property the model can be also estimated using a method-of-moments (MM) estimator (see Wang and Schmidt, 2002). In this case $\theta_{i t}$ can be written as a scaling function $h\left(z_{i}, \varphi\right)$ times a random variable $u_{i t}$ that does not depend on $z_{i t}$, that is ${ }^{18}$

\footnotetext{
${ }^{17} \mathrm{Kim}$ (2006) proposes a similar solution to address Corts' critique. He suggests modelling the conduct parameter as a core time-invariant conduct parameter, and a (linear) function of dynamic behaviour's determinants, i.e. demand and cost shocks.

${ }^{18}$ The scaling property in (5) corresponds to a multiplicative decomposition of $\theta_{i t}$. An alternative that has sometimes been proposed in the literature on frontier production functions (Huang and Liu, 1994; Battese
} 


$$
\theta_{i t} \rightarrow h\left(z_{i t}, \varphi\right) \cdot u_{i t} \cdot
$$

This property implies that changes in $z_{i t}$ affect the scale but not the shape of $u_{i t}{ }^{19}$ Except for the new vector of parameters, $\varphi$, the model to be estimated is the same as (4), and a MM estimator can be used if we assume, for instance, an exponential scaling function, i.e. $h\left(z_{i t}, \varphi\right)=\exp \left(z_{i t}{ }^{\prime} \varphi\right){ }^{20}$

\section{Estimation strategy}

We now turn to explaining how to estimate the pricing relationships presented in the previous section. Two estimation methods are possible: a method-of-moments (MM) approach and maximum likelihood (ML). The MM approach involves three stages. In the first stage, all parameters describing the structure of the pricing equation (i.e. cost, demand and dynamic parameters) are estimated using appropriate econometric techniques. In particular, because some regressors are endogenous, a generalized method of moments (GMM) method should be employed to get consistent estimates in this stage. ${ }^{21}$ This stage is independent of distributional assumptions on either error component. In the second stage of the estimation procedure, distributional assumptions are invoked to obtain consistent estimates of the parameter(s) describing the structure of the two error components, conditional on the first-stage estimated parameters. In the third stage, market power scores are estimated for each firm by decomposing the estimated residual into an error-term component and a market-power component.

The ML approach uses maximum likelihood techniques to obtain second-stage estimates of the parameter(s) describing the structure of the two error components, conditional on the first-stage estimated parameters. It can be also used to estimate simultaneously both types of parameters, if the endogenous regressors in the pricing equation are previously instrumented. In this case, the ML approach combines the two first stages of the method of moments approach into one.

While the first-stage is standard in the NEIO literature, the second and third stages take advantage of the fact that the conduct term is likely positively or negatively skewed, depending on the oligopolistic equilibrium that is behind the data generating process. Models with both symmetric and asymmetric random terms of the form in

and Coelli, 1995) is an additive decomposition of the form $\theta_{\mathrm{it}}\left(\mathrm{z}_{\mathrm{it}}, \varphi\right)=\mathrm{h}\left(\mathrm{z}_{\mathrm{it}}, \varphi\right)+\tau_{\mathrm{it}}$. However, this can never actually be a decomposition into independent parts, because $\theta_{\mathrm{it}}\left(\mathrm{z}_{\mathrm{it}}, \varphi\right) \geq 0$ requires $\tau_{\mathrm{it}} \leq \mathrm{h}\left(\mathrm{z}_{\mathrm{it}}, \varphi\right)$. ${ }^{19}$ Note the similarity of this multiplicative specification of the conduct term and Kim's (2007) additive specification. If firm's behaviour is influenced by expected future demand and expected future costs, this is captured by the scaling function $h\left(z_{i}, \varphi\right)$.

${ }^{20}$ Although it is an empirical question whether or not the scaling property should hold, it has some features that we find attractive. For instance, the interpretation of $\varphi$ does not depend on the distribution of $u_{i t}$, and simple scaling functions yield simple expressions for the effect of the $\mathrm{z}_{\mathrm{it}}$ on the dynamic conduct parameter $\theta_{\mathrm{it}}$. For example, if we use an exponential scaling function, so that $\theta_{i t}=\exp \left(z_{i t}{ }^{\prime} \varphi\right) \cdot u_{i t}$, then the coefficients $\varphi$ are just the derivatives of $\ln \left(\theta_{i t}\right)$ with respect to the $z_{i t}$, and have standard interpretations as marginal effects.

${ }^{21}$ The GMM estimator has the additional advantage over ML in that it does not require a specific distributional assumption for the errors, which makes the approach robust to nonnormality and heteroskedasticity of unknown term (Verbeek, 2000, p. 143). 
Section 2 have been proposed and estimated in the stochastic frontier analysis literature. $^{22}$

\subsection{First Stage: Pricing Equation Estimates}

Let us rewrite the pricing equation (4) as:

$$
P_{t}=m c\left(q_{i t}, \alpha\right)+g_{i t} \cdot \theta+\varepsilon_{i t},
$$

where $\alpha$ is the vector of cost parameters, ${ }^{23} \theta=E\left(\theta_{i t}\right)$, and

$$
\varepsilon_{i t}=v_{i t}+g_{i t} \cdot\left\{\theta_{i t}-\theta\right\} \text {. }
$$

The possible endogeneity of some regressors will lead to least squares being biased and inconsistent. This source of inconsistency can be dealt with by using GMM. Though first-step GMM parameter estimates are consistent, they are not efficient by construction because the $v_{i t}$ 's are not identically distributed. Indeed, assuming that $\theta_{i t}$ and $v_{i t}$, are distributed independently of each other, the second moment of the composed error term can be written as:

$$
E\left(\varepsilon_{i t}^{2}\right)=\sigma_{v}^{2}+g_{i t}^{2} \cdot \sigma_{\theta}^{2},
$$

where $E\left(v_{i t}{ }^{2}\right)=\sigma_{v}^{2}$, and $\operatorname{Var}\left(\theta_{i t}\right)=\sigma_{\theta}^{2}$. Equation (8) shows that the error in the regression indicated by (6) is heteroskedastic. Therefore an efficient GMM estimator is needed. Suppose that we can find a vector of $m$ instruments $M_{i t}$ that satisfy the following moment condition:

$$
E\left[M_{i t} \cdot \varepsilon_{i t}\right]=E\left[M_{i t} \cdot\left(P_{t}-m c\left(q_{i t}, \alpha\right)-g_{i t} \cdot \theta\right)\right]=E\left[m_{i t}(\alpha, \theta)\right]=0 .
$$

The efficient two-step GMM estimator is then the parameter vector that solves:

$$
(\hat{\alpha}, \hat{\theta})=\arg \min \left[\Sigma_{i} \Sigma_{t} m_{i t}(\alpha, \theta)\right]^{\prime} W^{-1}\left[\Sigma_{i} \Sigma_{t} m_{i t}(\alpha, \theta)\right],
$$

where $W$ is an optimal weighting matrix obtained from a consistent preliminary GMM estimator. $^{24}$

\subsection{Second Stage: Variance Decomposition}

The pricing equation (6) estimated in the first stage is equivalent to standard specification of a structural market power econometric model, where an industryaverage conduct is estimated (jointly with other demand and cost parameters in most applications). As we mentioned earlier in the introduction section, our paper aims to exploit the asymmetry of the composed error term (i.e. the skewness of the conduct

\footnotetext{
${ }^{22}$ See, in particular, Simar, Lovell and Vanden Eeckaut (1994), and the references in Kumbhakar and Lovell (2000).

${ }^{23}$ In the empirical illustration below we include a dummy variable for binding capacity constraints that helps explaining the differential of prices over marginal costs. This variable is interpreted here as a determinant of marginal cost.

${ }^{24}$ This optimal weighting matrix can take into account both heteroskedasticity and autocorrelation of the error term.
} 
random variable) to get firm-specific market power estimates in the second and third stages. These stages therefore are the core of this paper.

In the second stage of the estimation procedure, distributional assumptions are invoked to obtain consistent estimates of the parameter(s) describing the variance of $\theta_{i t}$ and $v_{i t}\left(\right.$ i.e. $\sigma_{\theta}$ and $\sigma_{\mathrm{v}}$ ), conditional on the first-stage estimated parameters. ${ }^{25}$ This stage is critical as it allows us to distinguish variation in market conduct, measured by $\sigma_{\theta}$, from variation in demand and costs, measured by $\sigma_{\mathrm{v}}$. We can estimate $\sigma_{\mathrm{v}}$ and $\sigma_{\theta}$ using either MM or ML. ${ }^{26}$ Given that we have assumed a particular distribution for the conduct term, the ML estimators are obtained by maximizing the likelihood function associated to the error term $\widetilde{\varepsilon}_{i t}=v_{i t}+\tilde{\theta}_{i t}=v_{i t}+g_{i t} \theta_{i t}$ that can be obtained from an estimate of the first-stage pricing equation (6). The MM estimators are derived using the second and third moments of the error term in equation (6). The third moment of $\varepsilon_{\text {it }}$ can be written as:

$$
E\left(\varepsilon_{i t}^{3}\right)=g_{i t}^{3} \cdot E\left[\left(\theta_{i t}-\theta\right)^{3}\right] .
$$

Equation (11) shows that the third moment of $\varepsilon_{\mathrm{it}}$ is simply the third moment of the random conduct term, adjusted by $g_{i t}^{3}$. That is, while the second moment (8) provides information about both $\sigma_{\mathrm{v}}$ and $\sigma_{\theta}$, the third moment (11) only provides information about the asymmetric random conduct term. Now, if we assume a specific distribution for $\theta_{i t}$, we can infer $\sigma_{\theta}$ from (11), and then $\sigma_{\mathrm{v}}$ from (8). In practice, the MM approach has two potential problems. First, it is possible that, given our distribution assumptions, $\varepsilon_{i t}$ has the "wrong" skewness implying a negative $\sigma_{\theta}$. The second problem arises when $\varepsilon_{\text {it }}$ has the "right" skewness, but the implied $\sigma_{\theta}$ is sufficiently large to cause $\sigma_{v}<0$. Due to in earlier versions of the present study we got negative values using the MM approach in some time-periods and specification, in Section 4 we only report the results using the ML approach.

Whatever the approach we choose in the present stage, we need to choose a distribution for $\theta_{i t}$. The selected distribution for the random conduct term reflects the researcher's beliefs about the underlying oligopolistic equilibrium that generates the data. Therefore, different distributions for the conduct random term can be estimated to test for different types of oligopolistic equilibrium. The pool of distribution functions is, however, limited as we need to choose a simple distribution for the asymmetric term to be able to estimate the empirical model, while satisfying the restrictions of the economic theory The tractability principle prevents us from using more sophisticated distributions that, for instance, would allow us to model industries formed by two groups of firms with two different types of behaviour, i.e. an industry with two modes of the conduct term.

\footnotetext{
${ }^{25}$ Our approach can also be extended in order to allow for a heteroskedastic error term.

${ }^{26}$ Olson et al. (1980) showed that the choice of estimator (ML versus MM) depends on the relative values of the variance of both random terms and the sample size. When the sample size is large (as in our application) and the variance of the one-sided error component, compared to the variance of the noise term, is small the ML outperforms MM in a mean-squared error sense.
} 
The distribution for the asymmetric term adopted in this study is the doublebounded distribution that imposes both lower and upper theoretical bounds on the values of the random conduct term, i.e. $0 \leq \theta_{i t} \leq N$. In doing so, we follow Almanidis et al. (2011) who propose a model where the distribution of the inefficiency (here, the conduct) term is doubly truncated normal, that is, a normal distribution $\mathrm{N}\left(\mu, \sigma_{\mathrm{u}}\right)$ truncated at a point (say B) on the right tail as well as at zero. They also introduce the so-called truncated half normal model, which is a particular case of the doubly truncated normal when the mean of the pre-truncated normal distribution is zero (i.e. $\mu=0$ ), and the truncated exponential model, which is a distribution with similar characteristic than the truncated half normal model. In technical appendix, Table A.1, we reproduce the density functions of these double-bounded distributions, which are essential for both ML and MM estimation. As illustrated in technical appendix, Figure A.1, the modal value of the conduct random term varies with the value of $\mu$, the mean of the pretruncated normal distribution. ${ }^{27}$ The most frequent value of $\theta_{i t}$ is close to zero when $\mu=0$. In this case, higher values of $\theta_{i t}$ are increasingly less frequent. The modal value of $\theta_{i t}$ increases as long as $\mu \rightarrow \mathrm{N}$. The modal value is equal to the number of firms when $\mu=\mathrm{N}$, with less values of $\theta_{i t}$ increasingly less likely.

Once we impose that the upper bound is equal to the number of firms (i.e. $\mathrm{B}=\mathrm{N}$ ) these models can be used to estimate the distribution of the conduct term. The doubly truncated normal model is very flexible as it nests other one-sided distributions such as truncated normal or half normal. One desirable feature of this model is that the doubly truncated normal distribution may be either positively or negatively skewed. In particular, as illustrated in technical appendix, Figure A.1, it may exhibit (positive) negative skewness if the truncation on the right is closer (further than) to the mode than that on the left. And therefore it allows modelling oligopolistic equilibriums with a large fraction of firms behaving competitively, and vice versa.

An important caveat in estimating doubly truncated normal models is whether it is globally identifiable. Almanidis et al. (2011) show that when both the mean of the pre-truncated normal distribution $(\mu)$ and the upper-bound $(B)$ are estimated simultaneously, and the combination of these two parameters yield a (post-truncated) symmetric distribution identification problems may arise. Fortunately, these problems vanish in a structural model of market power because the upper-bound is fixed by the theory and it does not need to be estimated in practice.

\subsection{Third Stage: Obtaining Firm-Specific Market Power Estimates}

In the third stage we obtain the estimates of market power for each firm. From previous stages we have estimates of $\widetilde{\varepsilon}_{i t}=v_{i t}+g_{i t} \cdot \theta_{i t}=v_{i t}+\tilde{\theta}_{i t}$, which obviously contains information on $\theta_{i t}$. The problem is to extract the information that $\widetilde{\varepsilon}_{i t}$ contains on $\theta_{i t}$. Jondrow et al. (1982) face the same problem in the frontier production function

27 As shown by Almanidis et al. ( 2011, p.13), the mean of the conduct random term also varies with the value of $\mu$ :

$$
E\left(\theta_{i t}\right)=\mu+\frac{\xi_{1} \cdot \phi\left(\xi_{1}\right)-\xi_{2} \cdot \phi\left(\xi_{2}\right)}{\Phi\left(\xi_{2}\right)-\Phi\left(\xi_{1}\right)} \sigma_{u} \quad, \quad \xi_{1}=-\mu / \sigma_{u} \quad, \quad \xi_{2}=(B-\mu) / \sigma_{u}
$$


literature and propose using the conditional distribution of the asymmetric random term (here $\widetilde{\theta}_{i t}$ ) given the composed error term (here $\widetilde{\varepsilon}_{i t}$ ). In technical appendix, Table A.2 we provide several distributional assumptions for the analytical form for $E\left(\widetilde{\theta}_{i t} \mid \widetilde{\varepsilon}_{i t}\right)$, which is the best predictor of the conduct term (see Kumbhakar and Lovell, 2000, and Almanidis et al., 2011). ${ }^{28}$ Once we have a point estimator for $\widetilde{\theta}_{i t}$, a conduct score $\theta_{i t}$ can be obtained using the identity $\theta_{i t} \equiv \tilde{\theta}_{i t} / g_{i t}{ }^{29}$

Three comments are in order. First, although $\hat{\theta}_{i t}$ is the minimum mean squared error estimate of $\theta_{i t}$, and it is unbiased in the unconditional sense [ $E\left(\hat{\theta}_{i t}-\theta_{i t}\right)=0$ ], it is a shrinkage of $\theta_{i t}$ toward its mean (Wang and Schmidt, 2009). An implication of shrinkage is that on average we will overestimate $\theta_{i t}$ when it is small and underestimate $\theta_{i t}$ when it is large. This result, however, simply reflects the familiar principle that an optimal (conditional expectation) forecast is less variable than the term being forecasted. Second, so far we have assumed that the $\theta_{i t}$ are independent over time. Although independence is likely an unrealistic assumption, it is generally not clear how to relax it, i.e. how to allow for correlation over time in the random conduct term. ${ }^{30}$ However, Álvarez et al (2006) shown that estimates from (4) will be consistent even if the conduct term $\theta_{i t}$ is not independent over time, so long as the model is otherwise correctly specified. And third, in practice, this estimator uses the estimated $\sigma_{\mathrm{v}}$ as a measure of historical demand and cost random shocks, and adjusts the overall error term from "normal" random shocks in order to get an estimate of $\theta_{i t}$. Therefore, the estimated market power scores can be interpreted as mark-ups that cannot be explained by "normal" demand and cost random shocks.

\footnotetext{
${ }^{28}$ Both the mean and the mode of the conditional distribution can be used as a point estimator for the conduct term $\widetilde{\theta}_{i t}$. However, the mean is, by far, the most employed in the frontier literature.

${ }^{29}$ While we can get unbiased estimates of all parameters of the pricing equation (6) if $v_{i t}$ is heteroskedastic and it is ignored, an unwarranted assumption of homoskedasticity in $v_{i t}$ causes a wrong application of the conditional expectation that may bias the firm-specific conduct estimates. That is, estimating market power with a composed error model requires capturing not only the appropriate distribution for the conduct random term but also most of the variables which enters in the supply relationship because uncaptured differences among firms and over time might wrongly interpreted as differences or changes in conduct due to both phenomena shift the supply relationship. The procedure outlined above, however, can be generalized in order to accommodate for a heteroskedastic $v_{i t}$. This can be achieved by modelling the variance of $v_{i t}$ as a function of firm-specific size-related variables or, when a panel data is available, by estimating a different $\sigma_{\mathrm{v}}{ }^{2}$ for each firm.

${ }^{30}$ If scaling property is satisfied we may consider the following alternative model: $\theta_{i t}=h\left(z_{i t}, \varphi\right) \cdot u_{i}$, where $u_{i}$ is a time-invariant individual effect. This specification is a restricted version of (5) that implies that $\theta_{i t}$ only changes throughout the time-varying function $h\left(z_{i t}, \varphi\right)$. Models of this form have been proposed in the literature of production frontier functions, but all of this literature considered a "random-effects" treatment and proposed specific (truncated normal) distributions for the $u_{i}$, with estimation by maximum likelihood. Because some regressors are endogenous and might be correlated with random effects (i.e. $u_{i}$ ), a "fixed-effects" treatment or a generalized method of moments (GMM) method should be employed. Han, Orea and Schmidt (2005) shown, however, that a "fixed-effects" estimation of this type of models is not trivial due to the incidental parameters problem.
} 


\section{Empirical Application to California Electricity Market}

In this section we illustrate the proposed approach with an application to the California electricity generating market. This market was opened to competition in 1998 allowing firms to compete to supply electricity to the network. The wholesale prices stayed at "normal" levels from 1998 to May 2000, and skyrocketed during summer and fall 2000, resulting in breakdown of liberalized electricity market by the end of 2000. While California electricity crisis is a complex problem, driven by a number of factors, such as poor wholesale market design, absence of long-term contracting, unexpected increase in generation input costs, hike in end-use electricity demand due to unusually hot weather, a number of studies pointed to the evidence of significant market power in this restructured market. Borenstein (2002) and Wolak (2005) are two excellent surveys of the California electricity market restructuring disaster.

Our empirical application analyzes the competitive behavior of five strategic large firms from Puller's (2007) study of monopoly power in California restructured electricity markets using the same sample period (from April 1998 to November 2000). Following Borenstein et al. (2002), Kim and Knittel (2006), and Puller (2007), we define five large firms that owned fossil-fueled generators (AES, DST, Duke, Reliant and Southern) as 'strategic' firms, i.e. pricing according to equation (1). The competitive fringe includes generation from nuclear, hydroelectric, and small independent producers, and imports from outside California. Puller (2007, p.77) argues that these suppliers were either relatively small or did not face strong incentives to influence the price. ${ }^{31}$ Other studies (Bushnell and Wolak 1999, Borenstein et al 2008), however, find that competitive fringe occasionally did have incentives to act strategically and bid elastic supply and demand schedules to counter exercise of market power by the strategic firms. Because electricity storage is prohibitively costly, both strategic and non-strategic firms had to produce a quantity equal to demand at all times. ${ }^{32}$ The five large firms and a competitive fringe interacted daily in a market where rivals' costs were nearly common knowledge, which created strong incentives for tacit collusion (Puller, 2007). And the residual demand for electricity was highly inelastic,

\footnotetext{
${ }^{31}$ Specifically, Puller (2007) argued that independent and nuclear units were paid under regulatory side agreements, so their revenues were independent of the price in the energy market. The owners of hydroelectric assets were the same utilities that were also buyers of power and had very dulled incentives to influence the price. Finally, firms importing power into California were likely to behave competitively because most were utilities with the primary responsibility of serving their native demand and then simply exporting any excess generation.

${ }^{32}$ Modelling of market power in wholesale electricity markets becomes more complex if firms forwardcontract some of their output. As Puller (2007, p.85) notes, in the presence of unobserved contract positions the estimate of conduct parameters would be biased. This was generally not an issue in California wholesale electricity market during sample period. As Borenstein (2002, p. 199) points out, "Although the investor owned utilities had by 2000 received permission to buy a limited amount of power under long-term contracts, they were [...] still procuring about 90 percent of their "net short" position $[\ldots]$ in the Power Exchange's day-ahead or the system operator's real-time market. Puller (2007, p. 85) argues that "there is a widespread belief that in 2000 Duke forward-contracted some of its production." If data on contract positions were available, one could correct this bias by adjusting infra-marginal sales by the amount that was forward-contracted. Unfortunately, as in earlier studies on market power in California wholesale electricity market the contract positions are not observable in our dataset.
} 
which, given institutional weaknesses of California Power Exchange, allowed individual firms to raise prices unilaterally (Wolak, 2003).

We first carry out a standard econometric exercise and estimate consistently by GMM the parameters of the pricing equation (1). In particular, and in order to be sure that our first stage is sound, we try to reproduce Puller's (2007) results, using the same dataset, and the same specification for the pricing equation (1), and the same set of dependent and explanatory variables. ${ }^{33}$ Unlike Puller (2007) we use a different estimate of the elasticity of residual hourly demand function of the five strategic firms. This is because Puller (2007) does not observe actual residual demand schedules. Instead, he estimates the supply function of competitive fringe, and calculates the slope of the fringe supply, "which has the same magnitude but opposite sign of the slope of the residual demand faced by the five strategic firms" (Puller 2007, p. 78). This is problematic because Puller's (2007) estimates are correct if and only if the fringe firms act non-strategically (i.e. bid perfectly inelastic supply and demand schedules). As we noted above, this assumption is questioned by a number of studies. Instead we use the estimates of residual demand elasticities based on actual bids from California Power Exchange (PX) as suggested by Wolak (2003). For comparison purposes we also report the results based on Puller's (2007) elasticity estimates using the same definition of strategic/non-strategic firms.

After estimating the parameters of the pricing equation, we carry out the second and third stages assuming particular distributions for the conduct random term, all of them imposing the conduct term to be positive and less than the number of strategic firms.

\subsection{Pricing Equation and Data}

Following Puller (2007, eq. 3) the pricing equation to be estimated in the first stage of our procedure is:

$$
(P-m c)_{i t}=\alpha \cdot C A P B I N D_{i t}+\theta \cdot \frac{P_{t} q_{i t} / Q_{s t r a t, t}^{S}}{\eta_{s t r a t, t}^{D}}+\varepsilon_{i t},
$$

where $\alpha$ and $\theta=E\left(\theta_{i t}\right)$ are parameters to be estimated, $P_{t}$ is market price, $m c_{i t}$ is firm's marginal costs, $q_{i t}$ is firm's output, $C A P B I N D_{i t}$ is a dummy variable that is equal to 1 if capacity constraints are binding and equal to 0 otherwise, and $Q_{\text {strat } t}^{S}$ is total electricity

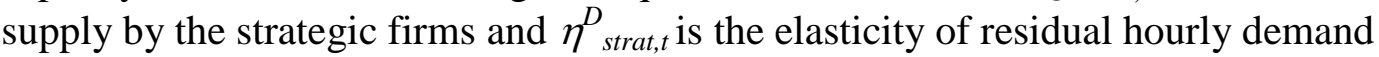
function of the five strategic firms.

We use hourly firm-level data on output and marginal cost. As in Puller (2007), we focus on an hour of sustained peak demand from 5 to 6 p.m. (hour 18) each day, when inter-temporal adjustment constraints on the rate at which power plants can increase or decrease output are unlikely to bind. Following Borenstein et al. (2002), we calculate the hourly marginal cost of fossil-fuel electricity plants as the sum of marginal

\footnotetext{
${ }^{33}$ Careful description of the dataset can be found in technical appendix in Puller (2007, pp.86-87).
} 
fuel, emission permit, and variable operating and maintenance costs. ${ }^{34} \mathrm{We}$ assume the marginal cost function to be constant up to the capacity of the generator. A firm's marginal cost of producing one more megawatt hour of electricity is defined as the marginal cost of the most expensive unit that it is operating and that has excess capacity.

Our measure of output is the total production by each firm's generating units as reported in the Continuous Emissions Monitoring System (CEMS), that contains data on the hourly operation status and power output of fossil-fuelled generation units in California. We use the California Power Exchange (PX) day-ahead electricity price, because $80 \%-90 \%$ of all transactions occurred in the PX. Prices vary by location when transmission constraints between the north and south bind. Most firms own power plants in a single transmission zone, so we use a PX zonal price. Table A.4 in technical appendix reports the summary statistics for all these variables.

We compute the value of the residual demand elasticity facing the five large suppliers evaluated at the hourly market clearing price, $P_{h}$, as described in Wolak (2003). We first compute the aggregate demand for electricity in the PX day-ahead energy market and subtract from that the total amount supplied at different prices in the neighborhood of the $P_{h}$ by all market participants besides five strategic firms. As the resulting residual demand curve is a step function, computing the slope of the residual demand curve at the $P_{h}$ involves some approximation. Wolak (2003) argues the approximation of the step function is reasonably accurate as there are large numbers of steps in the residual demand curve, particularly in the neighborhood of the marketclearing price. To compute the slope of the residual demand curve at the hourly marketclearing price, we find the closest price above $P_{h}$, such that the residual demand is less than the value at $P_{h}$. Following the notation in Wolak (2003), let $P_{h}$ (low) be this price, and $D R_{\text {strat } h}\left(P_{h}(\right.$ low $\left.)\right)$ be the associated value of the residual demand facing five strategic firms at $P_{h}$ (low). Next, we find the closest price below $P_{h}$ such that residual demand is greater than the value at $P_{h}$. Let $P_{h}($ high $)$ be this price, and $D R_{\text {strat }, h}\left(P_{h}(\right.$ high $\left.)\right)$ be the associated value of the residual demand facing five strategic firms at $P_{h}$ (high). The elasticity of the residual demand curve facing five strategic firms jointly during hour $h$ at price $P_{h}$ is equal to the arc elasticity, computed as

$$
\begin{aligned}
& \eta_{\text {strat }, h}^{D}=\frac{D R_{\text {strat }, h}\left(P_{h}(\text { high })\right)-D R_{\text {strat }, h}\left(P_{h}(\text { low })\right)}{P_{h}(\text { high })-P_{h}(\text { low })} \\
& \times \frac{P_{h}(\text { high })+P_{h}(\text { low })}{D R_{\text {strat }, h}\left(P_{h}(\text { high })\right)+D R_{\text {strat }, h}\left(P_{h}(\text { low })\right)}
\end{aligned},
$$

Following Wolak (2003) we set $P_{h}$ (low) and $P_{h}$ (high) equal to $\$ 1$ below and above $P_{h}{ }^{35}$

\footnotetext{
${ }^{34}$ We do not observe the spot prices for natural gas for California hubs in 1998 and 1999, and use prices from Henry Hub instead. The difference between natural gas prices between these hubs before 2000 (for which we have the data available) was relatively small (see Woo et al, 2006, p. 2062, Fig. 2).

${ }^{35}$ Wolak (2003) notes that this procedure does not guarantee that the difference between $D R_{\text {strat }, h}\left(P_{h}(\right.$ high $\left.)\right)$ and $D R_{\text {strat }, h}\left(P_{h}(\right.$ low $\left.)\right)$ is positive and therefore can produce zero values of $\eta_{\text {strat }, t}^{D}$. We used $\$ 0.50, \$ 1$, and $\$ 5$ to determine $P_{h}($ low $)$ and $P_{h}($ high $)$, and, similar to Wolak (2003), did not find noticeably different distributions of nonzero values of $\eta_{\text {strat }, \text {. }}^{D}$
} 
For comparison purposes we also replicate Puller's (2007) residual demand elasticity estimates to compute the expected value of the random conduct term. Puller (2007) computes residual demand elasticity as

$$
\eta^{D}{ }_{\text {strat }, t}=\hat{\beta} Q_{\text {fringe,t }}^{S} / Q_{\text {strat }, t}^{S},
$$

where $Q_{\text {fringe,t }}^{S}$ is electric power supply by the competitive fringe, and $\hat{\beta}=\frac{P_{t}}{P_{t}^{\prime} Q_{\text {fringe,t }}^{S}}$ is the price elasticity of the fringe supply. We obtain the estimates of $\hat{\beta}$ from Puller (2007, Table 3, p. 83).

Figure A.2 in technical appendix shows calculated price-cost margins. This figure is almost identical to Figure 1 in Puller (2007), and shows that margins vary considerably over sample period. They are also higher during the third and fourth quarters of each year, when total demand for electricity is high. Figure A.3 in technical appendix shows variation across time of the residual demand elasticities based on California PX bidding data and from Puller (2007). While both series exhibit similar trend, the elasticities based on PX data are considerably higher (in absolute terms) and more volatile. We next analyze the extent to which higher margins resulted from less competitive pricing behavior rather than from less elastic demand.

\subsection{Pricing Equation Estimates}

This section describes estimation results of pricing equation (6), which result in the first-stage parameter estimates. We consider different specifications, estimation methods, and time-periods. First, we estimate equation (6) using elasticities of residual demand, calculated based on PX data and based on Puller's (2007) estimates.

Second, we allow for output to be endogenous variable as the error term $\varepsilon_{\mathrm{it}}$ in (6) could include marginal cost shocks that are observed by the utility. ${ }^{36}$ To account for endogeneity of output we estimate equation (6) by the ordinary least squares (OLS), treating $P_{t} \cdot q_{i t} / Q_{\text {strat }, t}^{S}$ (hereafter $x_{i t}$ ) as exogenous variable, and by GMM using instruments for $x_{i t}$. We use four instruments for $x_{i t}$ : the inverse of the day-ahead forecast of total electricity output, $1 / F Q_{t}$, the dummy variable for binding capacity constraints, $C A P B I N D_{i t}$, the ratio of one week lagged output to current output, $Q_{t-7} / Q_{t}$, and firm's generation capacity, $k_{i t}$. The first two instruments are from Puller (2007). ${ }^{37} \mathrm{We}$ assume that the ratio of one week lagged output to current output is exogenous based on the standard argument in economic literature that unpredictable random variables do not affect realizations of firms' past planning decisions (Hall, 1988). We assume that firm's generation capacity is orthogonal to the error term because it can be viewed as a quasifixed variable, independent of current levels of operation. We then perform Hansen's (1982) $J$ test, $F$-test for weak instruments (Staiger and Stock, 1997) and Hausman's

\footnotetext{
${ }^{36}$ Puller (2007) makes similar point.

${ }^{37}$ Puller (2007) adopts the day-ahead forecast of total electricity output, rather than it's inverse. We do not use the day-ahead forecast of total electricity output here as an instrument because it failed Hansen's (1982) $J$ test. Notwithstanding this difference, the economic interpretation of using this instrument is the same as in Puller (2007).
} 
(1978) specification test to test for overidentifying restrictions, instruments' strength, and consistency of the OLS estimates.

Finally, we estimate equation (6) over three periods described in Puller (2007). The first period from July 1998 to April 1999 covers four strategic firms (AES, DST, Duke, and Reliant). The second period from May 1999 to November 2000 covers five strategic firms following Southern entry. The sub-period from June 2000 to November 2000 covers the price run-up preceding collapse of California liberalized electricity market.

Tables 1a-1c summarize the specification, estimation and fit of the pricing equation (6) using different set of instruments and calculated elasticities of residual demand, over the periods analyzed in Puller (2007). All estimated values of the conduct parameter are statistically significant from zero. The results of Hansen's $J$ test and $F$ test for weak instruments indicate that the chosen instruments are generally valid ${ }^{38}$, whereas Hausman's (1978) specification test indicates that the OLS results are biased and inconsistent. The size of this OLS bias, (measured by the difference between OLS and GMM estimates) is large indicating a significant correlation between the term $x_{i t}$ and unobserved error term.

The columns 4 and 5 of Tables 1a-1c shows the estimated coefficients for the pricing equation (6) using residual demand elasticities calculated based on PX data. The GMM estimates of the conduct parameter are quite similar to those obtained by Puller (2007) over the periods between July 1998 - April 1999 and May 1999 to November $2000 .{ }^{39}$ However, there is a large difference in the conduct parameter estimates over the sub-period from June 2000 - November 2000, corresponding to the price run-up preceding collapse of California liberalized electricity market. The estimated value of the conduct parameter using residual demand elasticities calculated based on PX data is 2.75 , indicating that electricity prices over this period were significantly above Cournot levels. This difference highlights the importance of using more accurate elasticity estimates in the analysis of market power in electricity markets.

\footnotetext{
${ }^{38}$ Chosen Instruments fail Hansen's J test at 5\% level of significance over the period from July 1998 April 1999 and over the sub-period from June 2000 - November 2000 using residual demand elasticities calculated based on Puller's (2007) estimates.

${ }^{39}$ Compared to Puller's (2007) estimates, the estimated value of the conduct parameter is smaller over the period from July 1998 to April 1999 and larger over the period May 1999 to November 2000. However, in both cases it is not statistically different from Puller's (2007) estimate of 0.97.
} 
Table 1a. Pricing equation estimates (July 1, 1998 - April 15, 1999)

Dependent variable: $(P-m c)_{i t}$

No. of strategic firms: 4

Method: OLS and Two-step GMM ${ }^{(a)}$

\begin{tabular}{|c|c|c|c|c|c|}
\hline \multirow[b]{2}{*}{ Explanatory variables } & \multirow[b]{2}{*}{ Coef. } & \multicolumn{2}{|c|}{ Elasticities based on Puller (2007) } & \multicolumn{2}{|c|}{ Elasticities based on PX bids } \\
\hline & & OLS & $\mathrm{GMM}^{(\mathrm{b})}$ & OLS & $\mathrm{GMM}^{(\mathrm{b})}$ \\
\hline$C A P B I N D_{i t}$ & $A$ & $\begin{array}{l}-4.979 \\
(3.703)\end{array}$ & $\begin{array}{c}10.737 * * * \\
(4.211)\end{array}$ & $\begin{array}{c}36.667 * * * \\
(6.083)\end{array}$ & $\begin{array}{c}8.113 \\
(10.626)\end{array}$ \\
\hline$x_{i t}=P_{t} q_{i t} / \eta_{\text {strat }, t}^{D} Q_{\text {strat } t}^{S}$ & $\theta$ & $\begin{array}{c}1.416^{* * * *} \\
(0.067)\end{array}$ & $\begin{array}{c}0.945^{* * *} * \\
(0.062)\end{array}$ & $\begin{array}{c}0.125^{* * * *} \\
(0.043)\end{array}$ & $\begin{array}{c}0.741 * * * \\
(0.105)\end{array}$ \\
\hline Observations & & 864 & 864 & 864 & 864 \\
\hline Mean of the dependent variable & & 8.562 & 8.562 & 8.562 & 8.562 \\
\hline Standard error of residuals & & 13.144 & 14.175 & 20.282 & 28.339 \\
\hline Hausman test ${ }^{(\mathrm{c})}$ & & & $61.40^{* * *}$ & & $41.64 * * *$ \\
\hline Hansen test ${ }^{(\mathrm{c})}$ & & & $4.478^{* *}$ & & 1.783 \\
\hline Test for weak instruments ${ }^{(c)}$ & & & $226.5^{* * *}$ & & $32.6 * * *$ \\
\hline
\end{tabular}

Notes:

${ }^{(a)}$ Standard errors robust to heteroskedasticity in parenthesis. $*(* *)(* * *)$ stands for statistically significance at $10 \%(5 \%)(1 \%)$.

(b) Instruments: $C A P B I N D_{i t}, k_{i}, l / F Q_{t}$, where $\mathrm{FQ}$ is day-ahead forecast of total (perfectly inelastic) demand and $k_{i t}$ is capacity.

(c) Both Hausman and Hansen tests follow a $\chi^{2}$ distribution with 1 degree of freedom. The Hausman test is sometimes based in only one parameter in order to provide a positive value. The test for weak instruments follows F distribution with 2 and (obs-3) degrees of freedom. 
Table 1b. Pricing equation estimates (April 16, 1999 - November 30, 2000)

Dependent variable: $(P-m c)_{i t}$

No. of strategic firms: 5

Method: OLS and Two-step GMM ${ }^{(a)}$

\begin{tabular}{|c|c|c|c|c|c|}
\hline \multirow[b]{2}{*}{ Explanatory variables } & \multirow[b]{2}{*}{ Coef. } & \multicolumn{2}{|c|}{ Elasticities based on Puller (2007) } & \multicolumn{2}{|c|}{ Elasticities based on PX bids } \\
\hline & & OLS & $\mathrm{GMM}^{(\mathrm{b})}$ & OLS & $\mathrm{GMM}^{(\mathrm{b})}$ \\
\hline$C A P B I N D_{i t}$ & $A$ & $\begin{array}{c}-5.160 \\
(4.1898)\end{array}$ & $\begin{array}{c}30.011 * * * \\
(6.6913)\end{array}$ & $\begin{array}{c}76.591 * * * \\
(10.7768)\end{array}$ & $\begin{array}{c}50.393 * * * \\
(13.1902)\end{array}$ \\
\hline$x_{i t}=P_{t} q_{i t} / \eta_{\text {Puller }} Q_{\text {strat } t}^{S}$ & $\theta$ & $\begin{array}{l}1.363 * * * \\
(0.0585)\end{array}$ & $\begin{array}{c}0.801 * * * \\
(0.0343)\end{array}$ & $\begin{array}{c}0.065^{* * *} * \\
(0.0213)\end{array}$ & $\begin{array}{l}1.052 * * * \\
(0.1233)\end{array}$ \\
\hline Observations & & 2300 & 2300 & 2300 & 2300 \\
\hline Mean of the dependent variable & & 18.43 & 18.43 & 18.43 & 18.43 \\
\hline Standard error of residuals & & 27.83 & 34.80 & 57.689 & 80.768 \\
\hline Hausman test ${ }^{(c)}$ & & & $20.51 * * *$ & & $66.28 * * *$ \\
\hline Hansen test ${ }^{(\mathrm{c})}$ & & & 0.654 & & 1.413 \\
\hline Test for weak instruments ${ }^{(c)}$ & & & $412.5 * * *$ & & $71.6^{* * *}$ \\
\hline
\end{tabular}

Notes:

(a) Standard errors robust to heteroskedasticity in parenthesis. $*(* *)(* * *)$ stands for statistically significance at $10 \%(5 \%)(1 \%)$.

(b) Instruments: $C A P B I N D_{i t}, k_{i t}, Q(-7) / Q$, where $\mathrm{Q}(-7)$ is total demand lagged one week, and $k_{i t}$ is capacity.

(c) Both Hausman and Hansen tests follow a $\chi^{2}$ distribution with 1 degree of freedom. The Hausman test is sometimes based in only one parameter in order to provide a positive value. Test for weak instruments follows F distribution with 2 and (obs-3) degrees of freedom. 
Table 1c. Pricing equation estimates (June 1, 2000 - November 30, 2000)

Dependent variable: $(P-m c)_{i t}$

No. of strategic firms: 5

Method: OLS and Two-step GMM ${ }^{(a)}$

\begin{tabular}{|c|c|c|c|c|c|}
\hline \multirow[b]{2}{*}{ Explanatory variables } & \multirow[b]{2}{*}{ Coef. } & \multicolumn{2}{|c|}{ Elasticities based on Puller (2007) } & \multicolumn{2}{|c|}{ Elasticities based on PX bids } \\
\hline & & OLS & $\mathrm{GMM}^{(\mathrm{b})}$ & OLS & $\mathrm{GMM}^{(\mathrm{b})}$ \\
\hline$C_{A P B I N D_{i t}}$ & $\alpha$ & $\begin{array}{l}-2.286 \\
(7.714)\end{array}$ & $\begin{array}{c}32.685^{* * *} \\
(10.139)\end{array}$ & $\begin{array}{c}131.323 * * * \\
(17.981)\end{array}$ & $\begin{array}{c}100.462 * * * \\
(28.991)\end{array}$ \\
\hline$x_{i t}=P_{t} q_{i t} / \eta_{\text {Puller }} Q_{\text {strat }, t}^{S}$ & $\theta$ & $\begin{array}{c}1.408^{* * * *} \\
(0.061)\end{array}$ & $\begin{array}{c}1.065^{* * * *} \\
(0.041)\end{array}$ & $\begin{array}{l}0.069^{*} \\
(0.046)\end{array}$ & $\begin{array}{c}2.753 * * * \\
(0.552)\end{array}$ \\
\hline Observations & & 490 & 490 & 490 & 490 \\
\hline Mean of the dependent variable & & 75.614 & 75.614 & 75.614 & 75.614 \\
\hline Standard error of residuals & & 53.928 & 59.836 & 119.188 & 237.101 \\
\hline Hausman test ${ }^{(c)}$ & & & $28.23 * * *$ & & $24.621 * * *$ \\
\hline Hansen test $^{(\mathrm{c})}$ & & & $10.091 * * *$ & & $2.841^{*}$ \\
\hline Test for weak instruments ${ }^{(c)}$ & & & $405.1 * * *$ & & $22.99 * * *$ \\
\hline
\end{tabular}

Notes:

(a) Standard errors robust to heteroskedasticity in parenthesis. ***)(***) stands for statistically significance at $10 \%(5 \%)(1 \%)$.

(b) Instruments: $C A P B I N D_{i t}, k_{i t}, Q(-7) / Q$, where $\mathrm{Q}(-7)$ is total demand lagged one week, and $k_{i t}$ is capacity.

(c) Both Hausman and Hansen tests follow a $\chi^{2}$ distribution with 1 degree of freedom. The Hausman test is sometimes based in only one parameter in order to provide a positive value. Test for weak instruments follows F distribution with 2 and (obs-3) degrees of freedom. 


\subsection{Variance Decomposition}

Once all parameters of the pricing equation (6) are estimated, we can get estimates of the parameters describing the structure of the two error components included in the composed random term $\varepsilon_{i t}$ (second-stage). Conditional on these parameter estimates, market power scores can be then estimated for each firm by decomposing the estimated residual into a random error component and a market-power component (third-stage).

Following the discussion in the section 3.2, to obtain the estimates of the parameters describing the structure of error components we first need to specify the distribution of the unobserved random conduct term. We must also impose both lower and upper theoretical bounds on the values of the random conduct term, i.e. $0 \leq \theta_{i t} \leq N$. To achieve this objective, we consider the doubly truncated normal model introduced by Almanidis et al. (2011) that satisfies both theoretical restrictions. ${ }^{40}$

For robustness grounds, several specifications of the doubly truncated normal model were estimated, corresponding to different levels of $\mu$, i.e. the mean of the pretruncated random term that, after truncation, yields $\theta_{i t}$. In most of the models, we set the values of $\mu$ equal to 0,1 , and 2 because the conduct parameter estimated in the first stage of our procedure moved around one. An exception is the sub-period from June 2000 - November 2000 that covers the price run-up preceding collapse of California liberalized electricity market using the elasticities based on PX data. In this case, large (non-zero) modal values of $\theta_{i t}$ are expected given the large value of the conduct parameter estimated in the first-stage. For this reason, for this time frame and residual demand elasticities, we estimate doubly-truncated normal distribution models with $\mu$ equal 2, 3, and 4. As regards other specifications, setting for instance $\mu=0$ is infeasible because the mean of $\theta_{i t}$ cannot be higher than N/2 in this case, as it happens in our firststage estimates.

We then estimate the model using maximum likelihood and choose the preferred level of truncation based on the lowest value of the Akaike information criterion (AIC) from estimated specifications. In technical appendix, Table A.4, we show the performed test to select the value of the mean of the pre-truncated normal distribution, $\mu$. Table A. 4 shows that the preferred level of truncation is 0 across all specifications, except for sub-period from June 2000 - November 2000, where the preferred level of $\mu$ is 2 . In other words, the conduct random term in most cases can be modeled using the truncated half normal distribution that assumes zero modal value of $\theta_{i t}$. As expected, this specification is not appropriate for the sub-period from June 2000 to November 2000 using the elasticities based on PX data. For this model, the performed tests suggest using a doubly truncated normal distribution (with $\mu=2$ ).

\footnotetext{
${ }^{40}$ To measure the convenience of using double-bounded distributions in practice, in previous versions of the present paper we also estimated the traditional half-normal distribution, which only imposes the conduct term be positive. The market power scores for the half-normal distributions were, on average, much higher than the upper-bound indicated by the theory, indicating that the one-sided specifications, traditional in the stochastic frontier literature, should not be used in the present application, and theoryconsistent double-bounded distributions need to be estimated.
} 
Table 2 describes the parameter estimates of the doubly truncated normal model describing the structure of $\theta_{i t}$ and $v_{i t}$ (i.e. $\sigma_{\mathrm{u}}$ and $\sigma_{\mathrm{v}}$ ) across different specifications, conditional on the first-stage estimated parameters. ${ }^{41}$ In all cases, the conduct variance is much lower than the variance of the traditional error term. This outcome indicates that both demand and cost random shocks, which are captured by the traditional error term, explains most of the overall variance of the composed error term, $\sigma_{\varepsilon}$. Moreover, the variance of the traditional error term tends to higher over the period from May 1999 to November 2000, and especially high over the sub-period from June 2000 - November 2000 , corresponding to the price run-up. This observation is consistent with the timing of events preceding the collapse of the California electricity market, which included large variation in both electricity demand, and, especially, the natural gas prices (Borenstein, 2002). On the other hand, the variation of the random conduct term declines over the period from May 1999 to November 2000, and increases over the subperiod from June 2000 - November 2000, corresponding to the price run-up. This increase is especially high in specification using using residual demand elasticities calculated based on PX data. However, the variance estimate of the random conduct term over this subperiod is not statistically significant. These results indicate that, while changing market conditions created additional incentives for electric power generators to exercise market power, there was a variation in effective realization of market power.

This result is consistent with the evidence from earlier studies reporting strategic interaction between the utilities and electric power suppliers during the price-run up (Bushnell 1999, Borenstein et al 2008).

\subsection{Firm-specific market power scores}

Based on the previous estimates, the third stage allows us to get firm-specific market power scores. Table 3 provides the arithmetic average scores of each firm obtained using ML estimates of doubly truncated normal model. For comparison purposes we also report the firm-specific estimates of Puller (2007).

Table 3 illustrates several interesting points that are worth mentioning. First, like in Puller (2007), the estimated firm-level values of the conduct parameter are closer to Cournot $\left(\theta_{i t}=1\right)$ than to static collusion $\left(\theta_{i t}=\mathrm{N}\right)$ across all specifications, except for the subperiod from June 2000 - November 2000 using the elasticities based on PX data. As regards that specification, we do find average conduct parameter values $\theta_{i t}=2$ across all firms, indicating substantial market power. This result is consistent with earlier studies, which employed different methodologies (Borenstein at al., 2002, Wolak 2003). However, unlike Puller (2007), we do not find an increase in market power if we compare the average values in the first period with those obtained in the second, regardless which residual demand elasticity measure we use.

\footnotetext{
${ }^{41}$ We expect the average conduct obtained in both first and second stages of our procedure be in fact equivalent, what can be taken as a test for the validity of the specification.
} 
Table 2. Second-stage Parameter Estimates.

\begin{tabular}{|c|c|c|c|}
\hline & $\begin{array}{l}\text { July 1, } \\
1998 \text { - } \\
\text { April 15, } \\
1999\end{array}$ & $\begin{array}{c}\text { April 16, } \\
1998- \\
\text { November } \\
30,2000\end{array}$ & $\begin{array}{c}\text { June } 1 \text {, } \\
2000 \text { - } \\
\text { November } \\
30,2000\end{array}$ \\
\hline \multicolumn{4}{|l|}{ Elasticities based on Puller (2007) } \\
\hline First-stage average conduct: $\hat{\theta}=E\left(\theta_{i t}\right)$ & 0.945 & 0.801 & 1.065 \\
\hline$\sigma_{v}$ & $\begin{array}{c}8.918 * * * \\
(0.252)\end{array}$ & $\begin{array}{c}9.651^{* * *} * \\
(0.189)\end{array}$ & $\begin{array}{c}14.070 * * * \\
(1.147)\end{array}$ \\
\hline$\sigma_{u}$ & $\begin{array}{c}1.369 * * * \\
(0.067)\end{array}$ & $\begin{array}{c}0.952 * * * \\
(0.020)\end{array}$ & $\begin{array}{c}1.215^{* * *} * \\
(0.043)\end{array}$ \\
\hline$\mu$ & 0 & 0 & 0 \\
\hline Mean log-likelihood: & -3.758 & -4.095 & -5.046 \\
\hline Implicit average conduct: & 1.081 & 0.760 & 0.970 \\
\hline \multicolumn{4}{|l|}{ Elasticities based on PX bids } \\
\hline First-stage average conduct: $\hat{\theta}=E\left(\theta_{i t}\right)$ & 0.741 & 1.052 & 2.753 \\
\hline$\sigma_{v}$ & $\begin{array}{c}14.827 * * * \\
(0.405)\end{array}$ & $\begin{array}{c}56.609 * * * \\
(0.889)\end{array}$ & $\begin{array}{c}114.464 * * * \\
(3.845)\end{array}$ \\
\hline$\sigma_{u}$ & $\begin{array}{c}1.607 * * * \\
(0.135)\end{array}$ & $\begin{array}{c}0.624 * * * \\
(0.123)\end{array}$ & $\begin{array}{c}3.051 \\
(2.741)\end{array}$ \\
\hline$\mu$ & 0 & 0 & 2 \\
\hline Mean log-likelihood: & -4.201 & -5.465 & -6.211 \\
\hline Implicit average conduct: & 1.241 & 0.498 & 2.398 \\
\hline
\end{tabular}


Table 3. Firm-Specific Conduct Parameter Estimates

\begin{tabular}{|c|c|c|c|c|c|}
\hline \multirow[t]{2}{*}{ Firm } & \multicolumn{2}{|c|}{ Elasticities based on Puller (2007) } & \multicolumn{2}{|c|}{ Elasticities based on PX bids } & \multirow[t]{2}{*}{ Puller (2007) } \\
\hline & Mean & St.Dev. & Mean & St.Dev. & \\
\hline \multicolumn{6}{|c|}{ July 1, 1998 - April 15, 1999} \\
\hline AES & 0.98 & 0.32 & 1.17 & 0.43 & 0.99 \\
\hline DST & 1.28 & 0.59 & 1.31 & 0.31 & 5.15 \\
\hline Duke & 0.95 & 0.33 & 1.18 & 0.45 & 1.02 \\
\hline Reliant & 1.07 & 0.33 & 1.23 & 0.39 & 1.48 \\
\hline \multicolumn{6}{|c|}{ April 16, 1999 - November 30,2000} \\
\hline AES & 0.74 & 0.31 & 0.50 & 0.07 & 0.82 \\
\hline DST & 0.88 & 0.57 & 0.50 & 0.04 & 1.75 \\
\hline Duke & 0.58 & 0.41 & 0.49 & 0.07 & 0.81 \\
\hline Reliant & 0.71 & 0.30 & 0.50 & 0.06 & 1.01 \\
\hline Southern & 0.80 & 0.29 & 0.50 & 0.05 & 1.21 \\
\hline \multicolumn{6}{|c|}{ June 1, 2000 - November 30,2000} \\
\hline AES & 0.78 & 0.49 & 1.96 & 0.39 & 0.96 \\
\hline DST & 1.51 & 0.83 & 2.00 & 0.23 & 2.39 \\
\hline Duke & 0.87 & 0.59 & 1.92 & 0.36 & 1.15 \\
\hline Reliant & 0.83 & 0.44 & 1.98 & 0.37 & 1.19 \\
\hline Southern & 0.96 & 0.40 & 1.95 & 0.31 & 1.46 \\
\hline
\end{tabular}


Second, we find notable differences among utilities in terms of market power. This suggests that assuming a common conduct parameter for all firms is not appropriate. Puller (2007) found a similar outcome using a fixed-effect treatment for the conduct parameters. Here, this result is obtained without involving panel data estimators. Our procedure has the advantage over Puller's approach that it can be applied with cross-sectional data sets; when the time dimension of the data set is short; or when the available instruments are valid to estimate a common pricing equation to all observations (see Hansen tests in Tables $1 \mathrm{a}-1 \mathrm{c}$ ), but they are not valid when a separable pricing equation is estimated for each firm.

Third, as illustrated in technical appendix, Figure A.4, our approach based on the estimated distribution of the random conduct yields similar firm-specific market power scores than Puller (2007) using a fixed-effect approach. This result demonstrates that both approaches are, in practice, equivalent or interchangeable. Note, however, that Puller (2007) got conduct parameters larger than perfect collusion (i.e. $\theta_{\text {it }}>\mathrm{N}$ ), which is not supported by the economic theory. In particular, he pointed out that Dynegy's (i.e. DST) conduct parameter is biased upward (see last column in Table 7). Our approach based on the estimated distribution of the random conduct term does not suffer for this problem and allow us to avoid this bias as our point estimates for this firm are sound and satisfy the theoretical restrictions.

In a panel data setting the most important advantage of our methodology is that we can analyze changes in market conduct over time. Indeed, because our approach does not impose the restrictions on the temporal path of these scores, they are allowed to change from one day to another. In Figures $1 \mathrm{a}-1 \mathrm{c}, 2 \mathrm{a}-2 \mathrm{c}$, and $3 \mathrm{a}-3 \mathrm{c}$ we show the temporal evolution of the average market power scores of the four/five strategic firms during the periods analyzed in the present paper. ${ }^{42}$ Our results indicate that the estimated firm-specific conduct parameters do vary significantly across time. These results point to two interesting conclusions, which tend to hold across all estimated specifications and periods. First, estimated conduct parameter values exhibit greater variation, and on average tend to be higher in summer time, when the electricity demand is high. This result is consistent with the theoretical findings of Green and Porter (1984), who predict a procyclical behaviour pattern for the exercise of market power. Second, estimated firm-specific conduct parameters generally tend to move in the same direction across time. This result indicates that firms tend pursue similar market strategies across time, and is consistent with the implied equilibrium behaviour of repeated dynamic games in homogenous product market setting. The notable exception is Duke, whose market strategies are occasionally different from other firms. In the next subsection, we argue that such behavior can be in part explained by Duke's increased potential for exercising unilateral market power.

Figures $1 \mathrm{a}$ and $1 \mathrm{~b}$ show the intertemporal variation in estimated conduct parameters over the period from July 1, 1998 to April 15, 1999. Both figures show that during this period firms electricity pricing were at (or slightly above) Cournot levels. The sole exception is Dynegy, whose conduct was above Cournot level during summer

\footnotetext{
${ }^{42}$ To smooth the variation across time, we report the monthly moving averages of the estimated conduct parameter.
} 
Figure 1a. Firm-Specific Conduct Parameter Estimates (Monthly Averages over July 1, 1998 - April 15, 1999,

Elasticities based on Puller 2007)

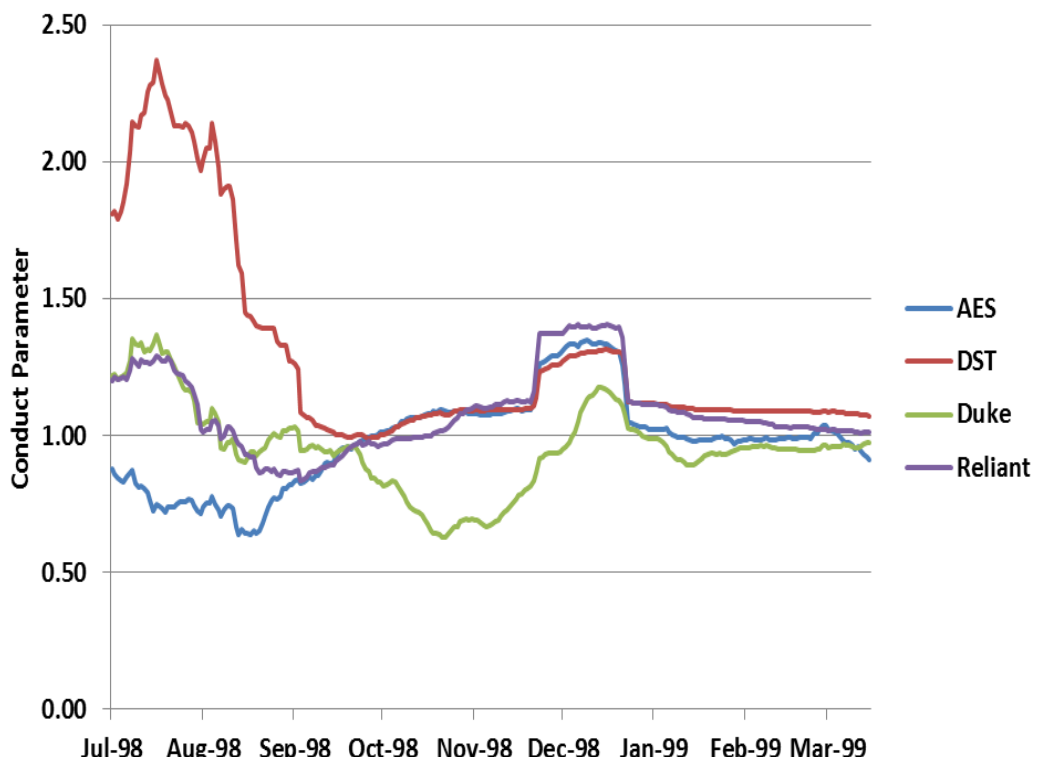

Figure 1b. Firm-Specific Conduct Parameter Estimates (Monthly Averages over July 1, 1998 - April 15, 1999, Elasticities based on PX Data)

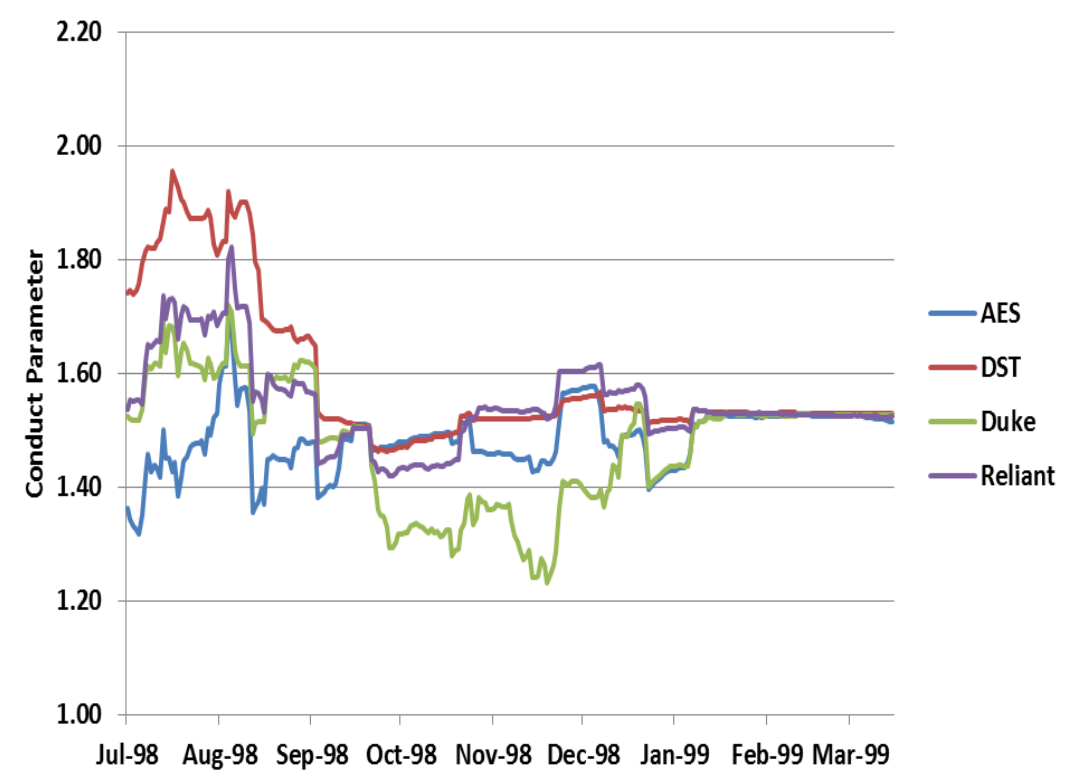


Figure 2a. Firm-Specific Conduct Parameter Estimates (Monthly Averages over April 16, 1999 - May 30, 2000, Elasticities based on Puller 2007)

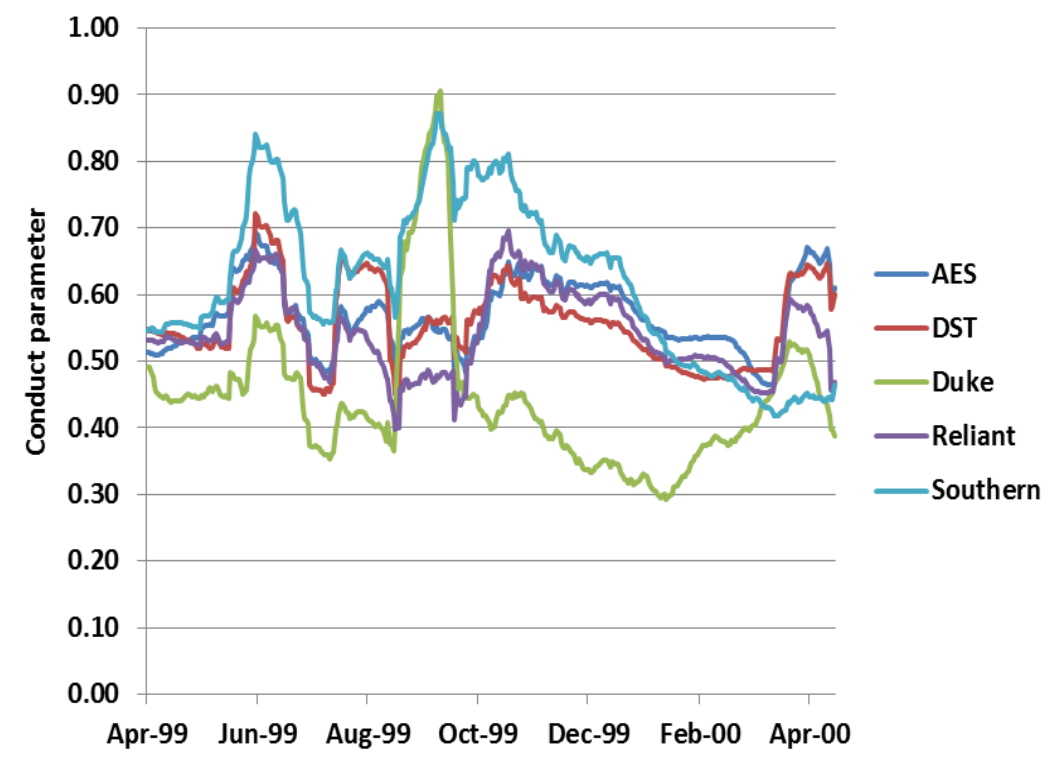

Figure 2b. Firm-Specific Conduct Parameter Estimates (Monthly Averages over April 16, 1999 - May 30, 2000, Elasticities based on PX Data)

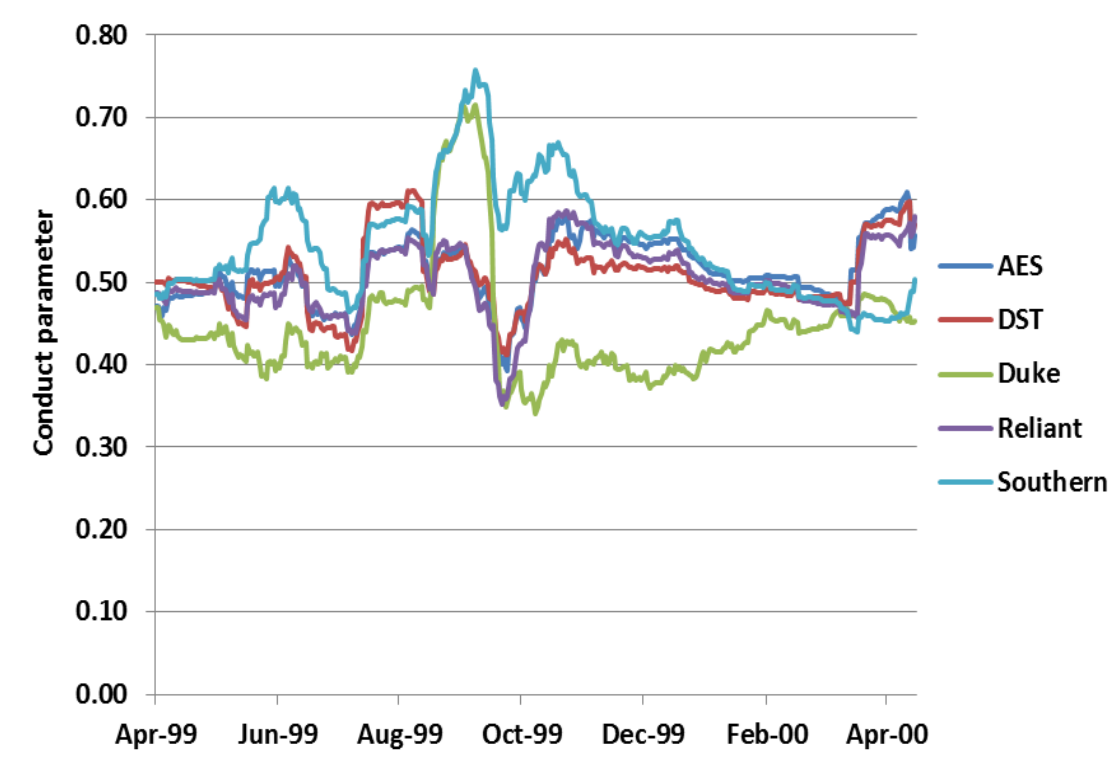


Figure 3a. Firm-Specific Conduct Parameter Estimates (Monthly Averages over June 1, 2000 - November 30, 2000,

Elasticities based on Puller 2007)

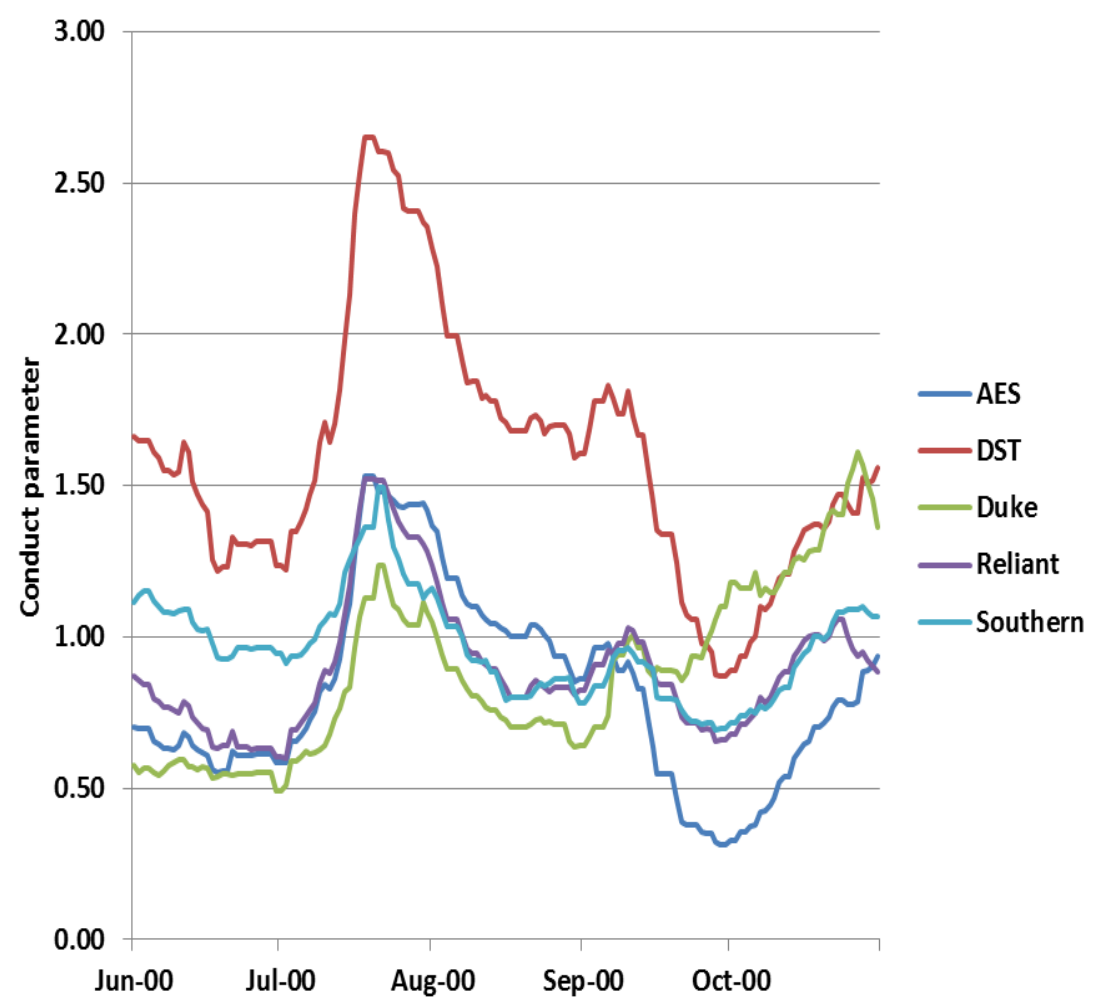

Figure 3b. Firm-Specific Conduct Parameter Estimates

(Monthly Averages over June 1, 2000 - November 30, 2000, Elasticities based on PX Data)

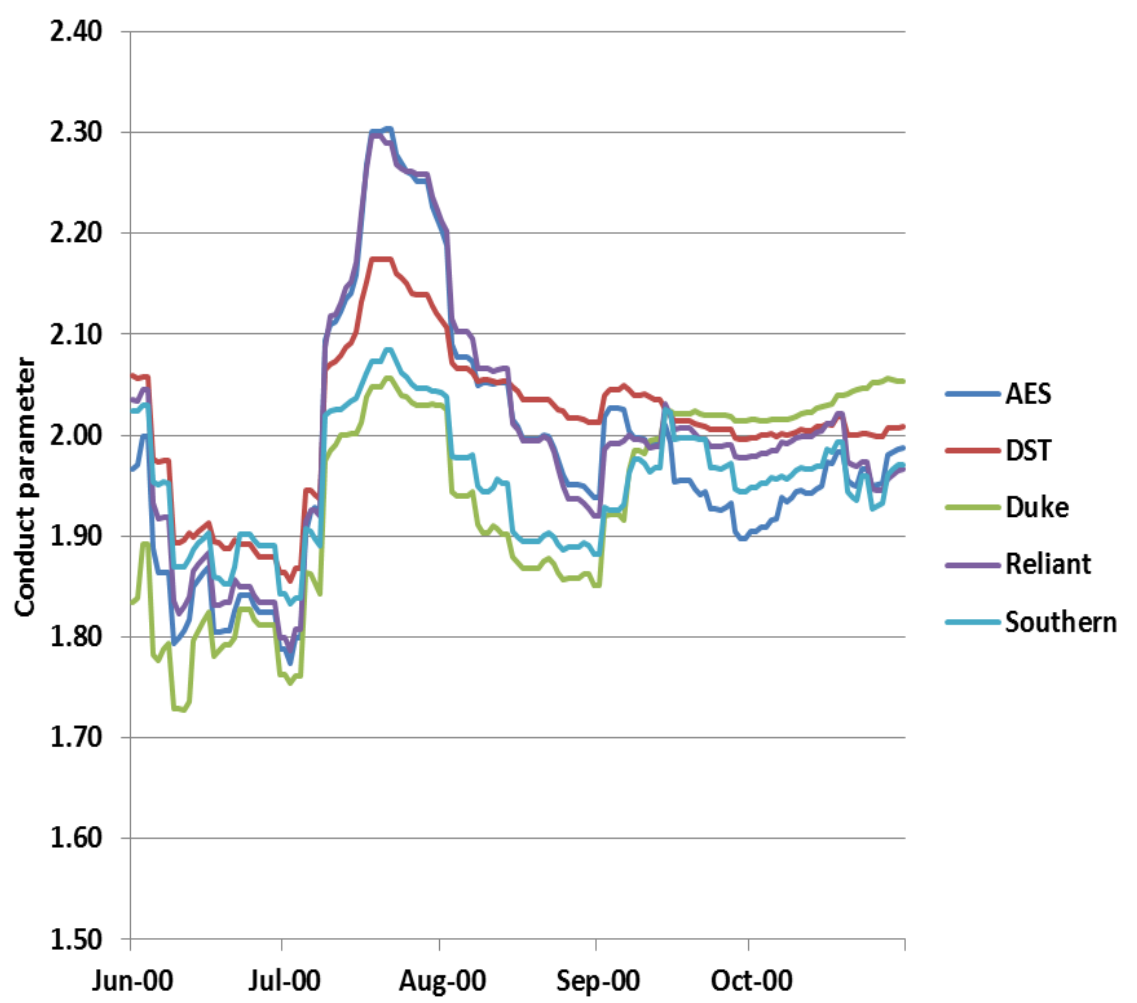


1998. Incidentally, Puller's (2007) time-invariant estimates also show that Dynegy had a higher value of estimated conduct parameter over this period. ${ }^{43}$

Figures $2 \mathrm{a}$ and $2 \mathrm{~b}$ show the intertemporal variation in estimated conduct parameters over the period from April 16, 1999 to May 30, 2000 following the entry of Southern. Both figures demonstrate that all firms' pricing strategies are below Cournot levels. Firms' pricing strategies exhibit a small variation during this period. On average, over this period, the new entrant Southern tends to have a higher value of estimated conduct parameter, whereas Duke tends to have a lower value of estimated conduct parameter.

Figures $3 \mathrm{a}$ and $3 \mathrm{~b}$ show the intertemporal variation in estimated conduct parameters over the sub-period of the price run-up from June 1, 2000 to November 30, 2000. Both periods indicate a substantial increase in the estimated conduct parameters between July and September, 2000. However, there is a large difference in the inferred firms' conduct for the results using the residual demand elasticities based on Puller (2007) and the residual demand elasticities based on PX bid data. The results using the residual demand elasticities based on Puller (2007) shown in Figure 3a, indicate that, with the exception of Dynegy, the pricing strategies of firms are consistent with Cournot levels. ${ }^{44}$ On the contrary, the results using the residual demand elasticities based on PX data shown in Figure 3b, indicate that all firms pricing strategies of firms are above Cournot levels. The most significant is simultaneous increase in estimated conduct parameter values for AES and Reliant (from 1.8 to 2.3), hinting at possible tacit collusion between two firms. ${ }^{45}$

\subsection{Unilateral vs. Coordinated Market Power}

Wolak (2003) used the actual bids submitted to the California Independent System Operator's real-time energy market, and demonstrated that residual demand curves facing five largest electric power suppliers were steep enough so that it was "unilaterally expected-profit-maximizing for each firm to bid to raise prices significantly in excess of the marginal cost of their highest-cost unit operating". ${ }^{46}$ Based on that finding, Wolak (2003) argued that the potential for exercising market power unilaterally "made collusive behavior on the part of suppliers to the California market unnecessary to explain the enormous increase in market power exercised starting in June 2000 ,47, although these considerations cannot rule out the possibility that collusive behavior took place.

We use the results of the analysis carried out in this paper to clarify the extent to which firms' potential for exercising market power unilaterally affects their market

\footnotetext{
${ }^{43}$ Puller (2007, p.84) suggests that these high conduct parameter estimates may result from incomplete quantity data for some of Dynegy's small peaker units.

${ }^{44}$ Puller (2007) rejects Cournot pricing for Dynegy and Southern over sub-period from June 1, 2000 to November 30, 2000.

${ }^{45}$ The California Public Utilities Commission (2002) found that those two firms have made the largest shares (respectively $46 \%$ and $42 \%$ ) of their capacity either out of service or not made available during blackouts and service interruptions in summer 2000.

${ }^{46}$ Wolak (2003, p.430)

${ }^{47}$ Ibid.
} 
conduct. In doing so, we follow Wolak (2003) and apply equation (13) to compute the residual demand elasticities facing each firm individually on the California PX market, and use their reciprocals (Lerner indices) as a measure of the firms' potential to exercise unilateral market power ${ }^{48}$. We then compare estimated firms' conduct parameters to calculated Lerner indices to deduct whether firms' conduct is correlated with higher potential for exercising of unilateral market power.

Figures $4 \mathrm{a}$ and $4 \mathrm{~b}$ show the variation of calculated Lerner indices across time over the periods from July 1, 1998 to April 15, 1999 (preceding entry of Southern), and from April 16, 1999 to November 30, 2000. For most of the sample period their values fluctuate between 0.05 and 0.15 , and are close to the averages reported in Wolak (2003, Table 1). However, for some periods, such as summers of 1998, 1999, and 2000, and the winters of 1998 and 1999 the values of calculated Lerner indices exceed 0.2, indicating substantial potential for the unilateral exercise of the market power.

The relationship between the calculated Lerner indices and the estimated conduct parameters is mixed, but most evidence shows that firms' market strategies tend to be closer to Cournot pricing, when their potential for the unilateral exercise of the market power increases. For example, the values of calculated Lerner indices were considerably higher for AES and Reliant between July and September, 1998; for Duke between October 1998 and January 1999; for AES and Southern between November and January 1999; for Duke between April and June 2000; and for Reliant and Southern between September and November 2000. For all those periods the values of conduct parameters of these firms tend to move towards $\theta_{i t}=1$. Similarly, over the period of highest values of conduct parameters in July - August 2000, the potential for exercising the unilateral market power was relatively small (except for Duke, which among five firms had the lowest value of the estimate conduct parameter). These results indicate that firms' willingness to engage in collusive behavior declines, when their potential for exercising unilateral market power increases.

There is also some evidence for the unidirectional movement of the calculated Lerner indices and the estimated conduct parameters. For example, there was a decline in both conduct parameter values and Lerner indices for Dynegy between July and September, 1998. Similarly, there was an increase both conduct parameter values and Lerner indices for Duke between September and November, 2000. These results indicate that even when the potential for exercising unilateral market power is high, firms may still have incentives to engage in collusive behavior.

\footnotetext{
${ }^{48}$ It is important to point out that because suppliers had the opportunity to sell their capacity in the CAISO ancillary services markets and the real-time energy market, the calculated Lerner indices are not the actual measure of the unilateral market power, unlike in Wolak (2003). Rather, we use this measure as a (maximum) potential for the unilateral exercise of the market power. However, given that PX market accounted for $85 \%$ of all electricity delivered in the CAISO control area, whereas CAISO's real time market accounted for just 5\% (Borenstein et al. 2002), and there was no substantial divergence between PX and ISO market clearing prices for the most of the time covered in this study (Borenstein et al. 2008) we believe our measure provides a reasonable approximation for the exercise of the unilateral market power.
} 
Figure 4a. Firm-Specific Lerner Indices

(Monthly Averages over July 1, 1998 - April 15, 1999,

Elasticities based on PX data)

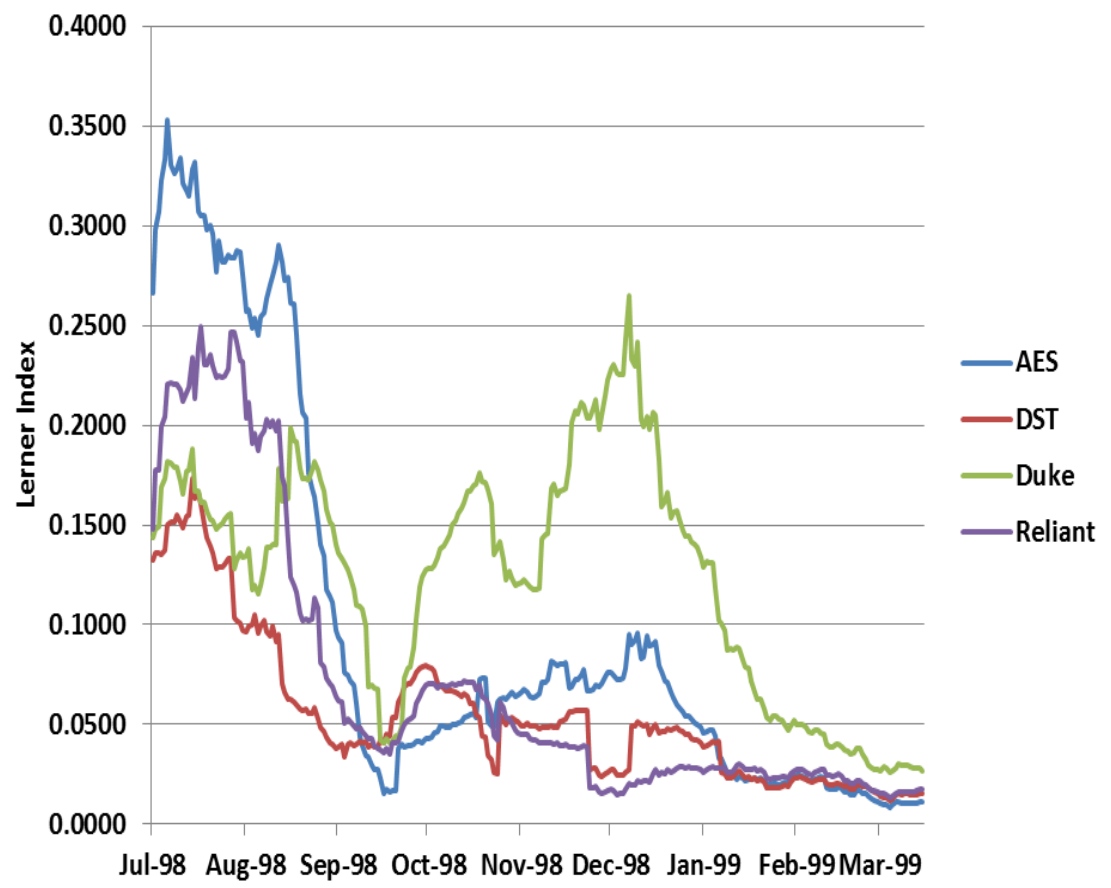

Figure 4b. Firm-Specific Lerner Indices

(Monthly Averages over April 16, 1999 - November 30, 2000,

Elasticities based on PX data)

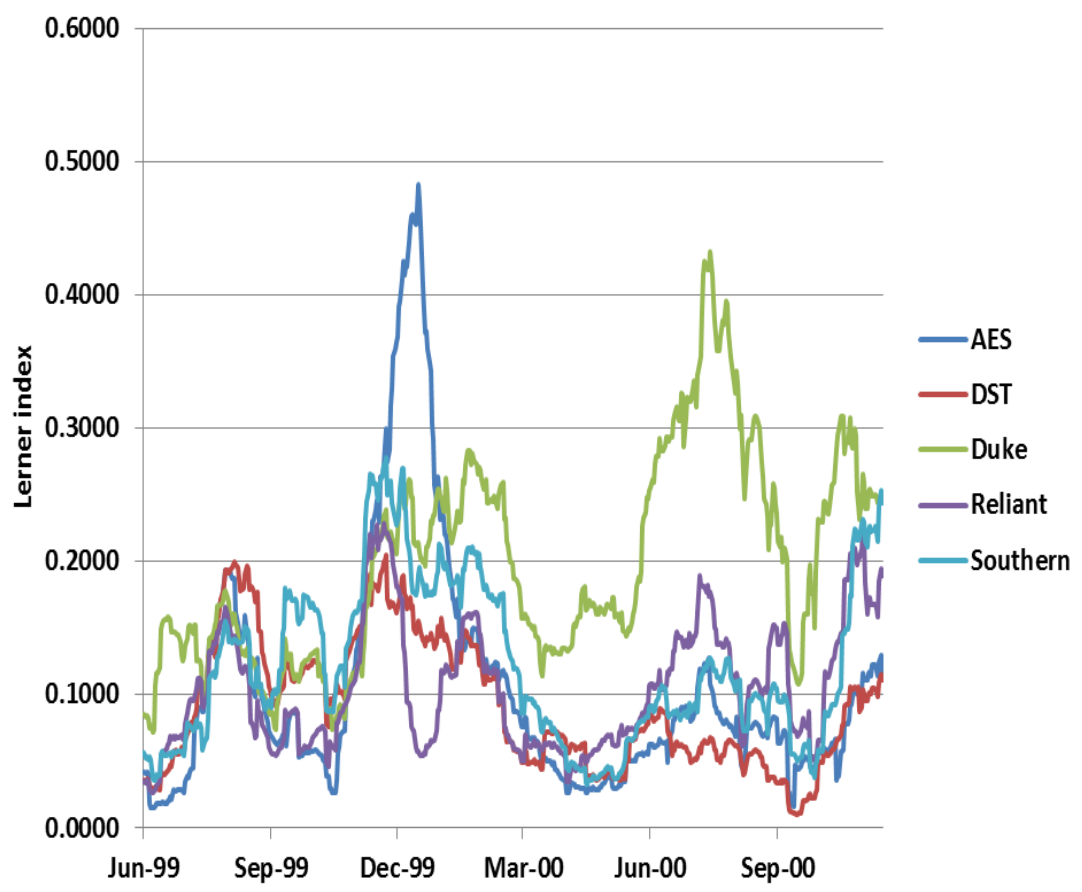




\section{Conclusions}

This study contributes to the literature on estimating market power in homogenous product markets. Our econometric approach allows for the value of estimated conduct parameter to vary across both firms and time. We estimate a composed error model, where the stochastic part of the firm's pricing equation is formed by two random variables: the traditional error term, capturing random shocks, and a random conduct term, which measures the degree of market power. Treating firms' behaviour as a random parameter helps solving the over-parameterization problem in the continuous time. Other advantages of our approach are its applicability to cross-sectional or short data sets, and when individual pricing equations cannot be consistently estimated with the available instruments. In addition, by imposing upper bound on the value of estimated conduct parameter we ensure that estimated market power scores are always consistent with the economic theory.

The model can be estimated in three stages using either cross-sectional or panel data sets. While the first stage of our model is the same as in the previous literature, the second and the third stages allow us to distinguish variation in market power from volatility in demand and cost, and get firm-specific market power scores, conditional on the first-stage parameter estimates. Model identification is based on the assumption that the conduct term is asymmetrically distributed, which, to our best knowledge, has not been previously used in the empirical industrial organization literature.

We illustrate the proposed approach with an application to the California wholesale electricity market using a well-known dataset from Puller (2007). We supplement the dataset with a different, and more accurate measure of the elasticity of residual hourly demand function of the five strategic firms, calculated based on California Power Exchange bidding data. After estimating the parameters of the pricing equation, we implement the second and third stages based on the truncated normal distributions, which imposes both lower and upper theoretical bounds on the values of the random conduct term.

Our first-stage results based on the estimated distribution of the random conduct are generally similar to previous findings of Puller (2007) using a fixed-effect approach. This result demonstrates that both approaches are, in practice, equivalent or interchangeable for estimating firms' pricing equation. However, our approach yields more reasonable market power scores than a fixed-effect treatment as estimated market power scores are always consistent with the economic theory.

The estimated market power values are closer to Cournot $\left(\theta_{i t}=1\right)$ than to static collusion $\left(\theta_{i t}=\mathrm{N}\right)$. However, we also find an increase in collusive behavior of all firms during the period of price run-up in June - November 2000, using the residual demand elasticities based on PX data. The analysis of firm-specific conduct parameters suggests that realization of market power varies over both time and firms. Firms' conduct tends to be procyclical, with the degree of collusive behaviour increasing (declining) during the periods of high (low) electricity demand. Firms' potential for realization of the market power unilaterally is generally associated with lower values of the conduct parameter, indicating that the unilateral exercise of market power and collusive behaviour are substitutes. 


\section{References}

Abreu, D. Pearce, D and Stacchetti, E. (1986), “Optimal Cartel Equilibria with Imperfect Monitoring", Journal of Economic Theory, 39, 251-269.

Álvarez, A., Amsler, C., Orea, L., and Schmidt, P. (2006), "Interpreting and Testing the Scaling Property in Models where Inefficiency Depends on Firm Characteristics", Journal of Productivity Analysis, 25, 201-212. Bounded Stochastic Frontiers with an Application to the US Banking Industry: 1984-2009

Almanidis, P, J. Qian, and R. Sickles (2011), "Bounded Stochastic Frontiers with an Application to the US Banking Industry: 1984-2009”, Working Paper, Rice University.

Appelbaum, E., (1982), “The Estimation of the Degree of Oligopoly Power," Journal of Econometrics, 19, 287-299.

Battese, G.E. and T.J. Coelli (1995), “A Model for Technical Efficiency for Panel Data”, Empirical Economics, 20, 325-332.

Borenstein, S. (2002), “The Trouble with Electricity Markets: Understanding California's Restructuring Disaster", Journal of Economic Perspectives, 16(1), 191-211.

Borenstein, S., J.B. Bushnell, and F.A. Wolak, (2002), "Measuring Market Inefficiencies in California's Restructured Wholesale Electricity Market", American Economic Review, 92, 1376-1405.

Borenstein, S., J. B. Bushnell, C. R. Knittel, and C. Wolfram, (2008), "Inefficiencies and Market Power in Financial Arbitrage: A Study of California's Electricity Markets", Journal of Industrial Economics, 56(2), 347-378.

Borenstein, S., and N.L. Rose (1994), "Competition and Price Dispersion in the US Airline Industry”, Journal of Political Economy, 102,653-683.

Borenstein, S. and A. Shepard (1996), "Dynamic Pricing in Retail Gasoline Markets", The RAND Journal of Economics, 27, 429-451.

Brander, A. J. and A. Zhang, (1993), "Dynamic Oligopoly Behavior in the Airline Industry", International Journal of Industrial Organization, 11, 407-435.

Bresnahan, T. (1989), "Empirical Studies of Industries with Market Power", in Schmalensee, R. and Willig, R. (eds), Handbook of Industrial Organization, Vol. 2, chapter 17, 1011-1057.

Bushnell, J. B., and F. A.Wolak, (1999), "Regulation and the Leverage of Local Market Power: Reliability Must-Run Contracts in the California Electricity Market", POWER working paper no. PWP-070, University of California Energy Institute.

California Public Utilities Commission, (2002), Executive Summary - Wholesale Generator Investigative Report. September 2002. Accessed online at http://www.hks.harvard.edu/hepg/Papers/CPUC_Wholesale.Gnerator.Investigati on.Report_9-02.pdf 
Chamberlain, G.C. (1980), "Analysis of Covariance with Qualitative Data", Review of Economics Studies, 47, 225-238.

Clay, K. and W. Troesken (2003), "Further Tests of Static Oligopoly Models: Whiskey, 1882-1898", Journal of Industrial Economics, 51(2), 151-166.

Corts, K. (1999), "Conduct Parameters and the Measurement of Market Power," Journal of Econometrics, 88, 227-250.

Ellison, G. (1994) "Theories of Cartel Stability and the Joint Executive Committee", Rand Journal of Economics, 25(1), 37-57.

Fried, H.,C. A. Knox Lovell, and Shelton S. Schmidt (2008), The Measurement of Productive Efficiency and Productivity Growth, Oxford University Press.

Gallet, A.G. and John R. Schroeter, (1995), "The Effects of the Business Cycle on Oligopoly Coordination: Evidence from the U.S. Rayon Industry", Review of Industrial Organization, 181-196.

Gollop, D., and Roberts, M., (1979), "Firm Interdependence in Oligopolistic Markets," Journal of Econometrics, 10, 313-331.

Genesove, D. and W. Mullin, (1994), "Testing Static Oligopoly Models: Conduct and Cost in the Sugar Industry, 1890-1914”, Rand Journal of Economics, 29(2), 355-377.

Green, E.J., Porter, R.H. (1984), "Noncooperative Collusion under Imperfect Price Information", Econometrica, 52, 87-100.

Hall, R.E. (1988), "Intertemporal Substitution in Consumption," The Journal of Political Economy, 96(2), 339-57.

Han, C., L. Orea, and P. Schmidt (2005),'Estimation of a Panel Data Model with Parametric Temporal Variation in Individual Effects", Journal of Econometrics, 126, 241-267.

Hansen, L.P. (1982), "Large Sample Properties of Generalized Method of Moments Estimators", Econometrica, 50, 1029-1054.

Hausman, J. A. (1978), “'Specification Tests in Econometrics”, Econometrica 46, $1251-1271$.

Huang, C.J. and J.T. Liu (1994),'Estimation of Non-neutral Stochastic Frontier production Function", Journal of Productivity Analysis, 5(2), 171-180.

Iwata, G., (1974), "Measurement of Conjectural Variations in Oligopoly," Econometrica 42, 949-966.

Jaumandreu, J., and J. Lorences (2002), "Modelling Price Competition across Many Markets (An Application to the Spanish Loans Market)," European Economic Review, 46, 93-115.

Jondrow, J., C.A.K. Lovell, S. Materov, and P. Schmidt (1982), "On the estimation of technical efficiency in the stochastic frontier production function model", Journal of Econometrics, 19(2/3), 233-238. 
Joskow, P.L. and E.Kahn (2002), “A Quantitative Analysis of Pricing Behavior In California's Wholesale Electricity Market During Summer 2000”, Energy Journal, 23, 1-35.

Kim, D. (2006), "Measuring Market Power in a Dynamic Oligopoly Model: The DallasForth Worth Milk Market Case", Economic Development \& Policy Series EDP06-4, GSIR Working Papers.

Kim, D.W., and C.R. Knittel (2006), "Biased in Static Oligopoly Models? Evidence from the California Electricity Market", Journal of Industrial Economics, Volume 54, No. 4, p. 451-470.

Kole, S. and K. Lehn (1999), "Deregulation and the Adaptation of Governance Structure: the Case of the U.S. Airline Industry", Journal of Financial Economics, 52, 79-117.

Kumbhakar, S.C. and Lovell, C.A.K. (2000), Stochastic Frontier Analysis. Cambridge University Press.

Nevo, A. (2001): "Measuring Market Power in the Ready-to-Eat Cereal Industry", Econometrica, 69(2), 307-342.

Olson, J.A., P. Schmidt, and D.M. Waldman (1980), "A Monte Carlo Study of Estimators of Stochastic Frontier Production Functions", Journal of Econometrics, 13(1), 67-82.

Perloff, J.M., L. Karp, and A. Golan (2007), Estimating Market Power and Strategies, Cambridge University Press.

Porter, R.H. (1983a). "A Study of Cartel Stability: The Joint Executive Committee, 1880-1886", Bell Journal of Economics 14(2), 301-314.

Porter, R.H. (1983b), "Optimal Cartel Trigger Price Strategies." Journal of Economic Theory, 29, 313-338.

Puller, S. (2009), "Estimation of Competitive Conduct when Firms are Efficiently Colluding: Addressing the Corts Critique" Applied Economics Letters, 16 (15), 1497-1500.

Puller, S. (2007), "Pricing and Firm Conduct in California's Deregulated Electricity Market", Review of Economics and Statistics, 89 (1),75-87.

Reiss, P.C. and F.A. Wolak (2007), "Structural Econometric Modeling: Rationales and Examples from Industrial Organization", Handbook of Econometrics, Volume 6, Elsevier B.V., p. 4280-4370.

Rigobon, R. (2003) "Identification through Heteroskedasticity", Review of Economics and Statistics, 85(4), 777-792.

Rotemberg, J.J., Saloner, G. A (1986), "Supergame-Theoretic Model of Price Wars During Booms", American Economic Review, 76, 390-407.

Simar, L., CAK Lovell, and P. Vanden-Eeckaut (1994), "Stochastic Frontiers Incorporating Exogenous Influences on Efficiency”, Discussion Paper No 9403, Institut de Statistique, Université Catholique de Louvain, Louvain-la-Neuve, Belgium. 
Staiger, D., and J. H. Stock (1997), “'Instrumental Variables Regression with Weak Instruments”, Econometrica, 65, 557-586.

Stigler, G.J. (1964), “A Theory of Oligopoly”, Journal of Political Economy, 72, 44-61.

Verbeek, M. (2000), A Guide to Modern Econometrics, John Wiley and Sons, First edition.

Wang, H.J. and P. Schmidt (2002), "One-Step and Two-Step Estimation of the Effects of Exogenous Variables on Technical Efficiency Levels," Journal of Productivity Analysis, 18, 129-144.

Wang, W.S. and P. Schmidt (2009), "On the Distribution of Estimated Technical Efficiency in Stochastic Frontier Models", Journal of Econometrics, 148, 36-45.

Wolak, F.A. (2003), "Measuring Unilateral Market Power in Wholesale Electricity Markets: The California Market, 1998-2000”, American Economic Review 93, 425-430.

Wolak, F.A. (2005), "Lessons from the California Electricity Crisis", in J.M. Griffin and S.L. Puller (eds.) Electricity Deregulation Choices and Challenges, University of Chicago Press.

Woo, C.K., A. Olson, I. Horowitzc, and S. Lu (2006), "Bi-directional Causality in California's Electricity and Natural-gas Markets”, Energy Policy 34, 2060-2070. 


\section{Technical Appendix}

Table A.1. Double-bounded density functions $(0 \leq \mathrm{u} \leq \mathrm{B})$

\begin{tabular}{|l|l|}
\hline Model & Density function of $f(\tilde{\varepsilon}=v+u)$ \\
\hline $\begin{array}{l}\text { Doubly truncated } \\
\text { normal }\end{array}$ & {$\left[\Phi\left(\frac{B-\mu}{\sigma_{u}}\right)-\Phi\left(\frac{-\mu}{\sigma_{u}}\right)\right]^{-1} \cdot \frac{1}{\sigma} \phi\left(\frac{-\varepsilon+\mu}{\sigma}\right)$.} \\
\hline$\left[\Phi\left(\frac{(B-\tilde{\varepsilon}) \lambda}{\sigma}+\frac{(B-\mu)}{\sigma \lambda}\right)-\Phi\left(-\frac{\tilde{\varepsilon} \lambda}{\sigma}-\frac{\mu}{\sigma \lambda}\right)\right]$ \\
\hline $\begin{array}{l}\text { Truncated half } \\
\text { normal }\end{array}$ & {$\left[\Phi\left(\frac{B}{\sigma_{u}}\right)-1 / 2\right]^{-1} \cdot \frac{1}{\sigma} \phi\left(\frac{-\varepsilon}{\sigma}\right) \cdot\left[\Phi\left(\frac{(B-\tilde{\varepsilon}) \lambda}{\sigma}+\frac{B}{\sigma \lambda}\right)-\Phi\left(-\frac{\tilde{\varepsilon} \lambda}{\sigma}\right)\right]$} \\
\hline $\begin{array}{l}\text { Truncated } \\
\text { exponential }\end{array}$ & $\frac{\exp \left(-\tilde{\varepsilon} / \sigma_{u}+\sigma_{v}^{2} / \sigma_{u}^{2}\right)}{\sigma_{u}\left(1-\exp \left(-\sigma_{u} / B\right)\right)}\left[\Phi\left(\frac{(B-\tilde{\varepsilon})}{\sigma_{v}}+\frac{\sigma_{u}}{\sigma_{v}}\right)-\Phi\left(\frac{-\tilde{\varepsilon}}{\sigma_{v}}+\frac{\sigma_{v}}{\sigma_{u}}\right)\right]$ \\
\hline
\end{tabular}

Table A.2. Conditional means for selected distributions

\begin{tabular}{|l|l|}
\hline \multicolumn{2}{|l|}{ One-sided distributions } \\
\hline Model & Functional form of $E(u \mid v+u)$ \\
\hline $\begin{array}{l}\text { Doubly truncated } \\
\text { normal }\end{array}$ & $\mu_{*}+\sigma_{*}\left[\phi\left(\frac{-\mu_{*}}{\sigma_{*}}\right)-\phi\left(\frac{B-\mu_{*}}{\sigma_{*}}\right)\left[\Phi\left(\frac{B-\mu_{*}}{\sigma_{*}}\right)-\Phi\left(\frac{-\mu_{*}}{\sigma_{*}}\right)\right]^{-1}\right.$ \\
& $\mu_{*}=\frac{\mu \sigma_{v}^{2}+\varepsilon \sigma_{u}^{2}}{\sigma^{2}}, \quad \sigma_{*}=\frac{\sigma_{u} \sigma_{v}}{\sigma}$ \\
$\begin{array}{l}\text { Truncated half } \\
\text { normal }\end{array}$ & $\mu_{*}+\sigma_{*}\left[\phi\left(\frac{-\mu_{*}}{\sigma_{*}}\right)-\phi\left(\frac{B-\mu_{*}}{\sigma_{*}}\right)\right]\left[\Phi\left(\frac{B-\mu_{*}}{\sigma_{*}}\right)-\Phi\left(\frac{-\mu_{*}}{\sigma_{*}}\right)\right]^{-1}$ \\
& $\mu_{*}=\frac{\varepsilon \sigma_{u}^{2}}{\sigma^{2}}, \quad \sigma_{*}=\frac{\sigma_{u} \sigma_{v}}{\sigma}$ \\
\hline
\end{tabular}


Table A. 3. Summary statistics (hour 18)

\begin{tabular}{|c|c|c|c|c|c|}
\hline \multicolumn{6}{|l|}{ July 1, 1998 - April 15, 1999} \\
\hline & Mean & St.dev. & $\underline{\text { Min }}$ & $\underline{\operatorname{Max}}$ & $\underline{\text { Obs }}$ \\
\hline Price $\left(P_{t}\right)$ & 35.2011 & 21.0092 & 4.93 & 180.446 & 864 \\
\hline Marginal cost $\left(m c_{i t}\right)$ & 26.6388 & 3.1341 & 19.4951 & 33.7443 & 864 \\
\hline $\operatorname{Margin}\left(P_{t}-m c_{i t}\right)$ & 8.5624 & 21.0473 & -24.978 & 158.611 & 864 \\
\hline$C A P B I N D_{i t}$ & 0.0486 & 0.2152 & 0 & 1 & 864 \\
\hline Capacity $\left(k_{i t}\right)$ & 2463.34 & 1053.83 & 670 & 3879 & 864 \\
\hline Output $\left(q_{i t}\right)$ & 813.338 & 843.671 & 0 & 3720 & 864 \\
\hline Market demand $\left(Q_{t}\right)$ & 30394.9 & 4146.02 & 20057 & 43847 & 864 \\
\hline Elasticities based on PX bids & 6.9127 & 6.3617 & 0.05 & 24.65 & 864 \\
\hline Elasticities based on Puller (2007) & 2.1200 & 1.326 & 0.5585 & 10.7715 & 864 \\
\hline \multicolumn{6}{|l|}{ April 16, 1999 - November 30, 2000} \\
\hline & $\underline{\text { Mean }}$ & $\underline{\text { St.dev. }}$ & $\underline{\text { Min }}$ & $\underline{\operatorname{Max}}$ & $\underline{\mathrm{Obs}}$ \\
\hline Price $\left(P_{t}\right)$ & 61.1741 & 68.3617 & 9.5 & 750 & 2300 \\
\hline Marginal cost $\left(m c_{i t}\right)$ & 42.7362 & 22.864 & 22.3039 & 214.473 & 2300 \\
\hline $\operatorname{Margin}\left(P_{t}-m c_{i t}\right)$ & 18.4379 & 57.3491 & -33.358 & 697.101 & 2300 \\
\hline CAPBIND $_{i t}$ & 0.047 & 0.2116 & 0 & 1 & 2300 \\
\hline Capacity $\left(k_{i t}\right)$ & 2954.86 & 769.463 & 1020 & 3879 & 2300 \\
\hline Output $\left(q_{i t}\right)$ & 1223.45 & 793.426 & 0 & 3317 & 2300 \\
\hline Market demand $\left(Q_{t}\right)$ & 30603.7 & 3657.65 & 22076 & 42404 & 2300 \\
\hline Elasticities based on PX bids & 4.0231 & 4.3458 & 0.01 & 24.89 & 2300 \\
\hline Elasticities based on Puller (2007) & 1.0181 & 0.6808 & 0.3505 & 5.2562 & 2300 \\
\hline \multicolumn{6}{|l|}{ June 1, 2000 - November 30, 2000} \\
\hline & $\underline{\text { Mean }}$ & $\underline{\text { St.dev. }}$ & $\underline{\text { Min }}$ & $\underline{\operatorname{Max}}$ & $\underline{\text { Obs }}$ \\
\hline Price $\left(P_{t}\right)$ & 148.966 & 106.471 & 43.15 & 750 & 490 \\
\hline Marginal cost $\left(m c_{i t}\right)$ & 73.3518 & 34.3946 & 40.4401 & 214.473 & 490 \\
\hline $\operatorname{Margin}\left(P_{t}-m c_{i t}\right)$ & 75.6139 & 102.286 & -23.05 & 697.101 & 490 \\
\hline CAPBIND $_{i t}$ & 0.1122 & 0.316 & 0 & 1 & 490 \\
\hline Capacity $\left(k_{i t}\right)$ & 2971.07 & 766.967 & 1474 & 3879 & 490 \\
\hline Output $\left(q_{i t}\right)$ & 1882.44 & 749.931 & 0 & 3317 & 490 \\
\hline Market demand $\left(Q_{t}\right)$ & 32619.6 & 4258.98 & 24932 & 42404 & 490 \\
\hline Elasticities based on PX bids & 5.2805 & 5.3084 & 0.02 & 22.21 & 490 \\
\hline Elasticities based on Puller (2007) & 0.4909 & 0.1094 & 0.3505 & 1.0029 & 490 \\
\hline
\end{tabular}


Table A.4. Selection of Pre-truncated Mean

\begin{tabular}{|c|c|c|c|c|c|c|}
\hline \multirow[t]{2}{*}{ Time Frame } & \multicolumn{3}{|c|}{ Elasticities based on Puller (2007) } & \multicolumn{3}{|c|}{ Elasticities based on PX bids } \\
\hline & \multicolumn{3}{|c|}{ 1st-stage conduct parameter ${ }^{(a)}$} & \multicolumn{3}{|c|}{ 1st-stage conduct parameter ${ }^{(a)}$} \\
\hline July, 1998 - April, 1999 & 0.945 & $(0-2)$ & & 0.741 & $(0-2)$ & \\
\hline April, 1999 - November, 2000 & 0.801 & $(0-2)$ & & 1.052 & $(0-2)$ & \\
\hline \multirow[t]{2}{*}{ June, 2000 - November, 2000} & 1.065 & $(0-2)$ & & 2.753 & $(2-4)$ & \\
\hline & \multicolumn{3}{|c|}{ Mean log-likelihood $(\mu=0,1,2)$} & \multicolumn{3}{|c|}{ Mean log-likelihood $(\mu=0,1,2)^{(b)}$} \\
\hline July, 1998 - April, 1999 & -3.7588 & -3.7754 & -3.8782 & -4.2015 & -4.2175 & -4.2381 \\
\hline April, 1999 - November, 2000 & -4.0949 & -4.1849 & -4.5869 & -5.4655 & -5.4836 & -5.5267 \\
\hline \multirow[t]{2}{*}{ June, 2000 - November, 2000} & -5.0462 & -5.0632 & -5.5635 & $-6.2119^{(\mathrm{c})}$ & $-6.2122^{(c)}$ & $-6.2122^{(c)}$ \\
\hline & \multicolumn{3}{|c|}{ Akaike Information Criterion (AIC) } & \multicolumn{3}{|c|}{ Akaike Information Criterion (AIC) } \\
\hline July, 1998 - April, 1999 & 6499.21 & 6527.98 & 6705.60 & 7264.35 & 7291.84 & 7327.52 \\
\hline April, 1999 - November, 2000 & 18840.54 & 19254.54 & 21104.11 & 25145.58 & 25228.70 & 25427.19 \\
\hline June, 2000 - November, 2000 & 4949.34 & 4966.02 & 5456.27 & $6069.69^{(\mathrm{c})}$ & $6078.18^{(\mathrm{c})}$ & $6091.71^{(c)}$ \\
\hline
\end{tabular}

\footnotetext{
Notes:
(a) Range of probable pre-truncated means in parenthesis.

(b) Except other range is explicitly indicated.

(c) In this case we set $\mu=2,3$, and 4 based on the higher value of the 1st-stage estimate of the conduct parameter.

(d) The values, which correspond to the minimal value of AIC are shown in bold.
} 
Figure A.1. Double-bounded distributions
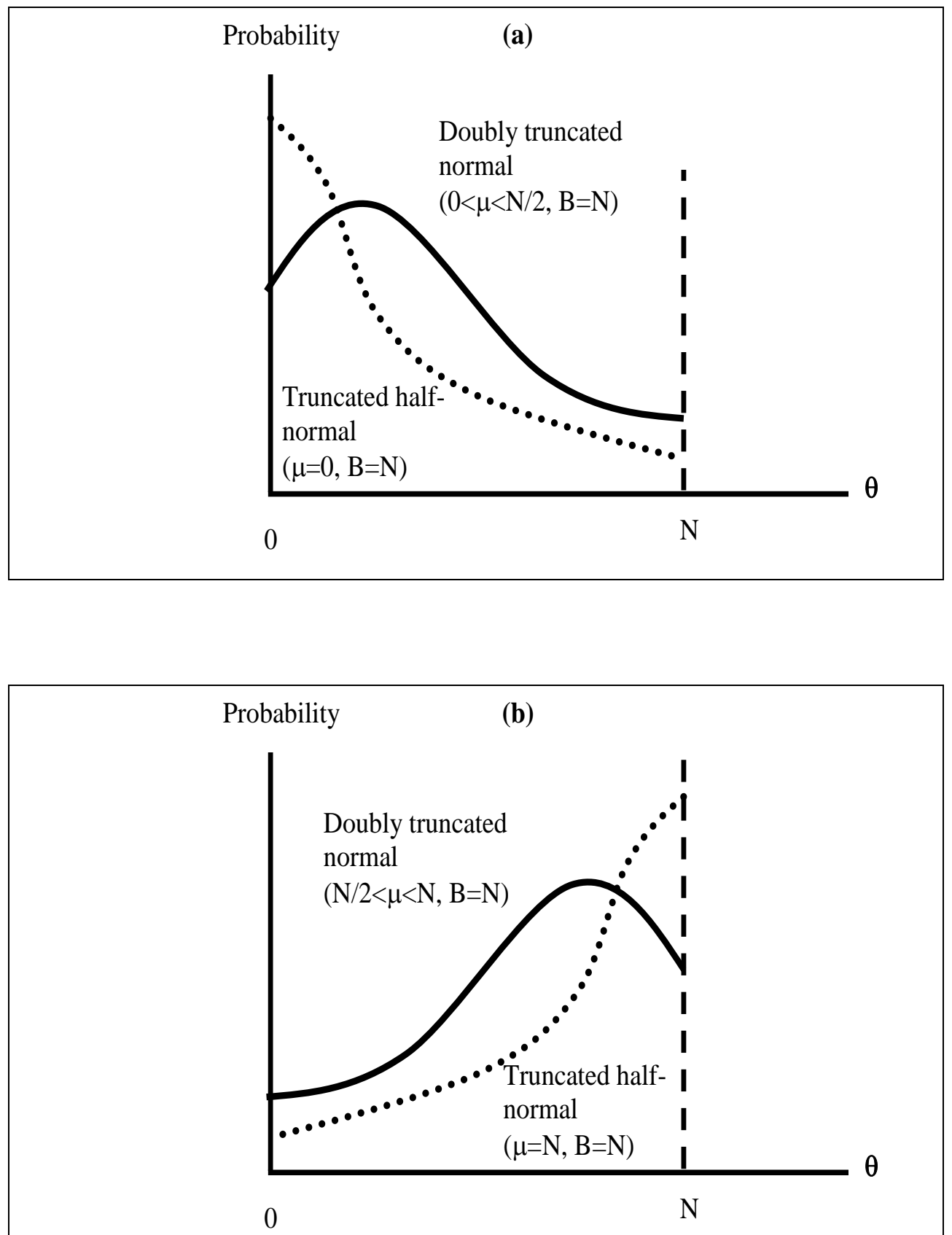
Figure A.2. Price-cost margins in hour 18 (July 3, 1998 - November 30, 2000)

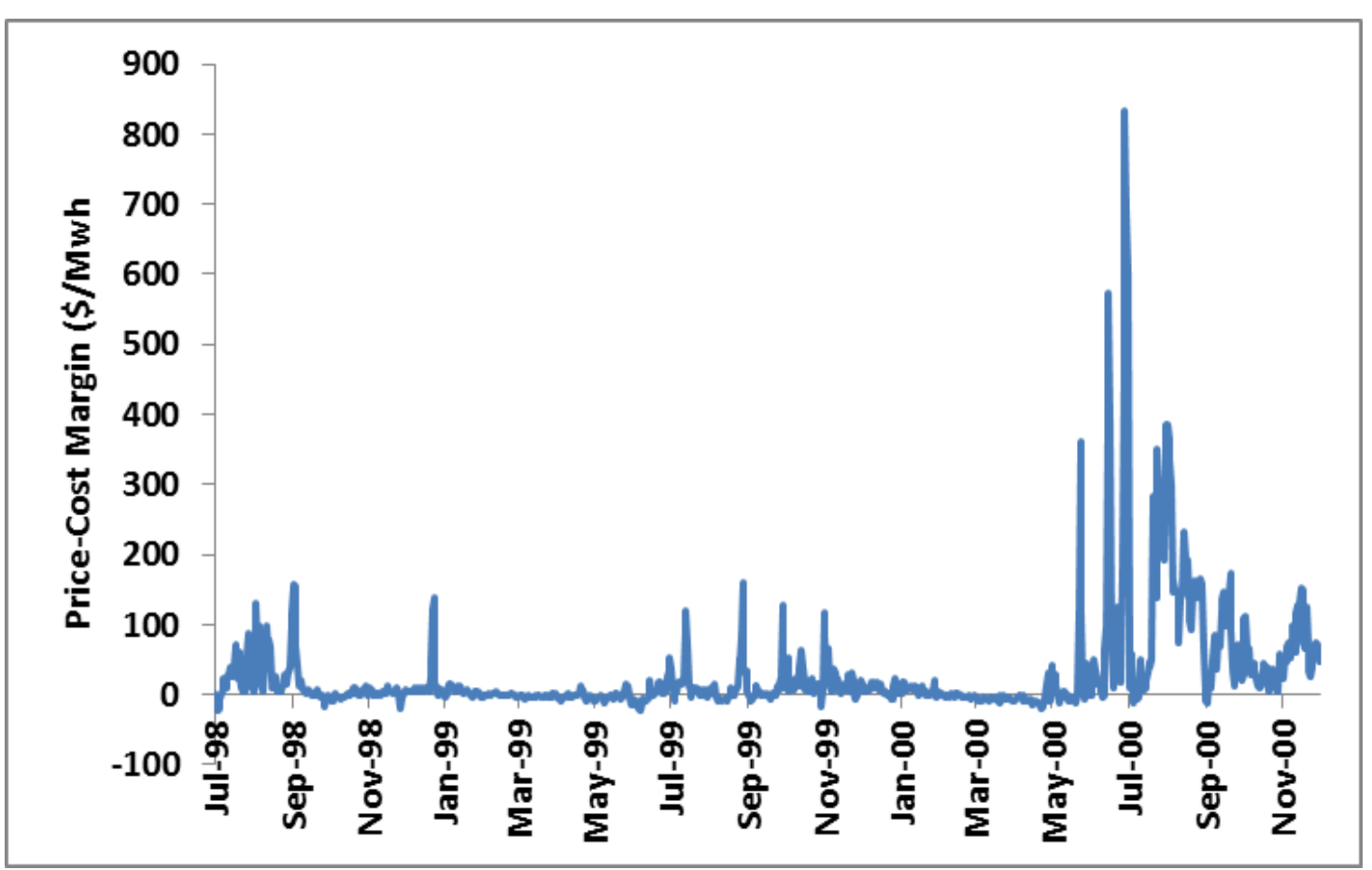


Figure A.3. Residual Demand Elasticities Facing Strategic Firms in hour 18 (Median Monthly Absolute Values, July, 1998 - November, 2000)

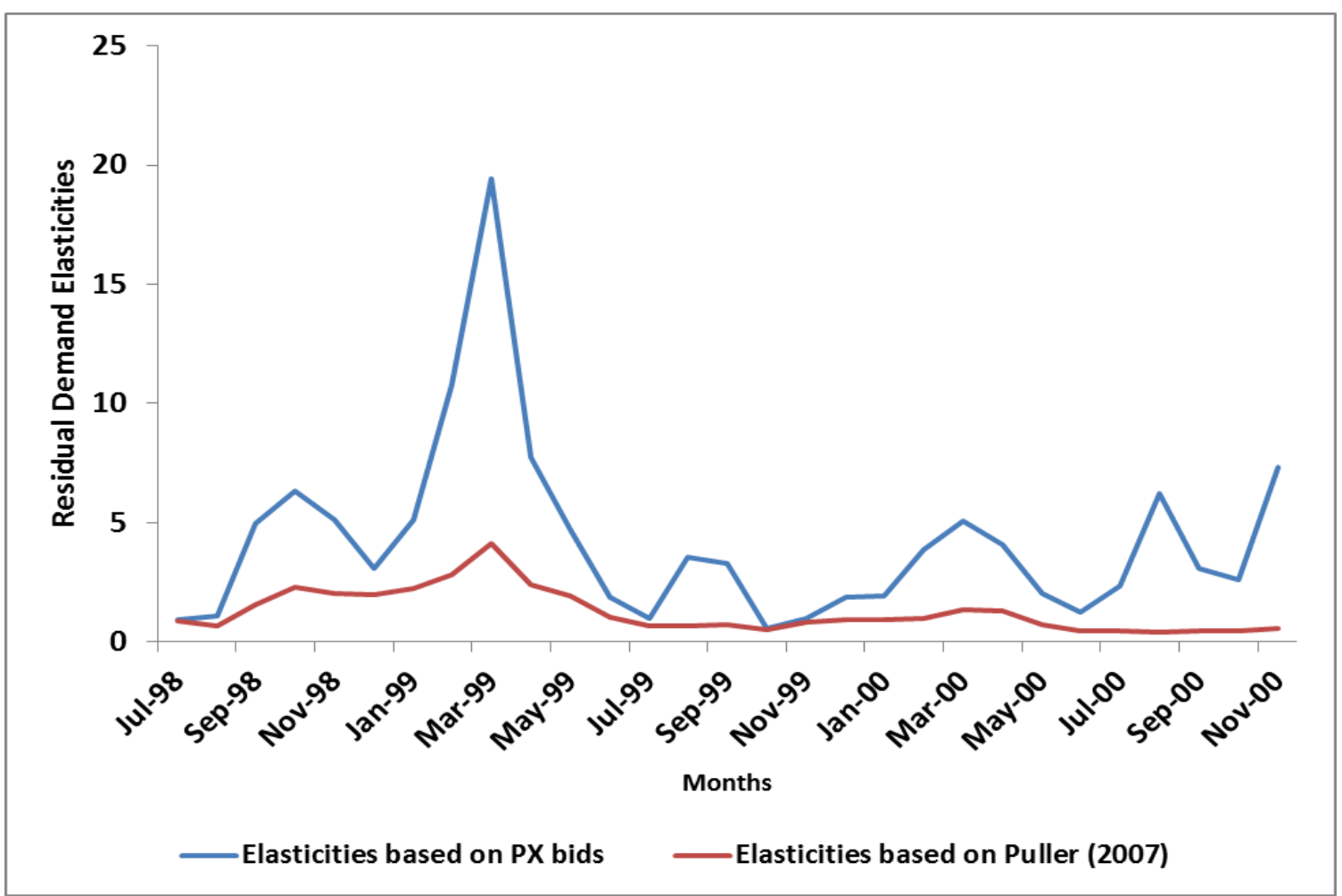


Figure A.4. Comparison of market power scores using elasticities based on Puller (2007).

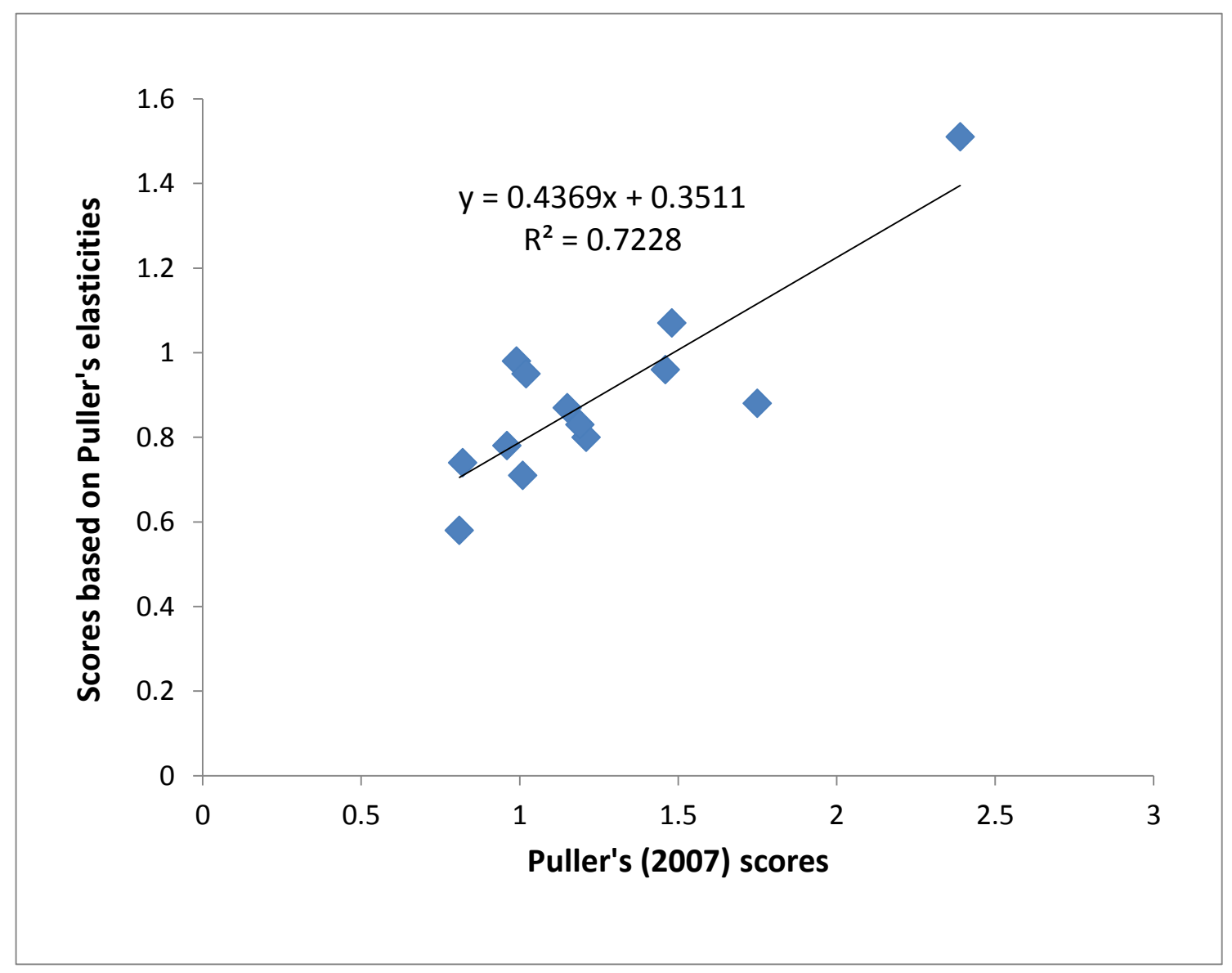

